\title{
An Investigation of Mesoscale Flows Induced by Vegetation Inhomogeneities Using an Evapotranspiration Model Calibrated Against HAPEX-MOBILHY Data
}

\author{
JeAN-PIERRE PINTY, PATRICK MASCART, EVELyNE RICHARD AND ROBERT ROSSET \\ Observatoire de Physique du Globe de Clermont-Ferrand, Laboratoire de Météorologie Physique, \\ Université Blaise Pascal, Aubière, France
}

(Manuscript received 31 October 1988, in final form 24 February 1989)

\author{
ABSTRACT
}

\begin{abstract}
Many recent studies have suggested that heterogeneities in soil properties or vegetation characteristics may trigger mesoscale circulations in the planetary boundary layer (PBL). Unfortunately, these flows appear to be very sensitive to the choice of the model characteristics and therefore require a careful calibration of the parameterization representing the vegetation/atmosphere interface.

In this paper, the micrometeorological data from the HAPEX-MOBILHY field experiment are used to calibrate an evapotranspiration parameterization scheme over three types of dense vegetation typical of western Europe. This parameterization is then used in a $2 \mathrm{D}$ mesoscale model to investigate the atmospheric response to a discontinuity in vegetation type (cereal crop to conifer forest). The results show a significant circulation when the soil is moist, associated with substantial PBL modification, whereas only a negligible atmospheric response is obtained when the soil is dry in the cereal crop area. A precise knowledge of the soil moisture therefore appears to be required, even with dense vegetation cover, to use advanced evapotranspiration schemes in mesoscale models.
\end{abstract}

\section{Introduction}

The importance of land surface characteristics in generating mesoscale circulations has been increasingly recognized in recent years. The most widely studied phenomenon is the atmospheric response associated with differences in soil moisture availability with no vegetation cover. Zhang and Anthes (1982), for example, have shown that variations in soil moisture have more significant effects on PBL characteristics than changes of surface albedo, surface roughness or soil thermal capacity. In a two-dimensional study, Ookouchi et al. (1984) showed that the differential heating associated with variations in soil moisture can produce circulations similar to a sea breeze, with a maximum vertical velocity of $22 \mathrm{~cm} \mathrm{~s}^{-1}$. Mahfouf et al. (1987a) obtained similar results considering two soils of different textures (clay and sand), but with the same relative moisture content, and concluded that the soil texture has a large influence on surface moisture availability. In a recent paper, Yan and Anthes (1988) found that inhomogeneities in soil moisture on a horizontal scale of $100-200 \mathrm{~km}$ can initiate convective rainfall in a convectively unstable environment with sufficient moisture and no synoptic flow.

Corresponding author address: Jean-Pierre Pinty, Observatoire de Physique du Globe de Clemont-Ferrand, Laboratoire de Meteorologie Physique, Universite Blaise Pascal, Avenue Des Landais, 63177 Aubiere Cedex France.
The mesoscale response to variations in vegetation characteristics has been studied much less. Anthes (1984) hypothesized that planting bands of vegetation with widths of 50 to $100 \mathrm{~km}$ in semiarid regions could produce atmospheric circulations and result in an increase of convective rainfall under favourable synoptic conditions. In a three-dimensional numerical study of South Florida, McCumber (1980) found that the presence of vegetation enhances the sensible flux to the atmosphere and modifies the sea-breeze convergence. Garrett (1982), comparing a meteorological model with large scale observations over the southern United States, suggested that forest coverage and transpiration may affect the formation of convective clouds and rainfall through their effect on the boundary layer growth. More recently, Mahfouf et al. (1987a), extending the bare soil study of Ookouchi et al. (1984) to vegetated surface conditions, indicate significant ascending motion in the transition zone between bare soil and vegetation-covered soil. In the same paper, they suggest that a uniform vegetation cover can curtail the mesoscale circulation produced by soil moisture heterogeneities.

Most of these sometimes contradictory studies, however, rely on complex surface flux computations which depend heavily on a large set of vegetation parameters. Clearly, the prescription of such a large parameter set is a difficult task. For example, Sellers and Dorman (1987) examined the partitioning of energy between sensible and latent fluxes in the Simple Bio- 
sphere model ( $\mathrm{SiB}$ ) of Sellers et al. (1986) and concluded that it is highly sensitive to the choice of the vegetation characteristics. Under typical conditions, they found that the uncertainties in the calculated evapotranspiration rates are as large as $\pm 25 \%$. This is confirmed by the study carried out by Wilson et al. (1987) for the Biosphere-Atmosphere Transfert Scheme (BATS) used in the NCAR community model, showing a significant sensitivity to changes in soil characteristics. Accordingly, it is highly desirable to use biophysically realistic initial conditions and carefully calibrated schemes in order to obtain consistent conclusions regarding the atmospheric response to given land-surface conditions.

This paper is an attempt to examine the influence of vegetation-type variations on the development of mesoscale circulations. The methodology used is very similar to the one of Mahfouf et al. (1987a). In order to isolate the influence of surface conditions, a flat terrain and clear sky nonperturbed synoptic environment are considered. The most original aspect of the work, however, is the use of micrometeorological, biophysical and soil measurements from the HAPEX-MOBILHY ${ }^{1}$ field experiment (André et al. 1986, 1988a) to improve the soil-vegetation scheme of Mahfouf et al. (1987a) and to prescribe realistic soil and vegetation characteristics. The paper is divided into three sections. Section 1 presents the modifications made to the soil-vegetation scheme in order to have a better control of the canopy transpiration by the water availability to the plant system. In section 2, measurements from two cereal crop sites and a forested site of HAPEX-MOBILHY are used to assess the scheme performance. In section 3 , the same scheme is used in a two-dimensional simulation to investigate the mesoscale response to the thermal and hydrological contrasts between a conifer forest and an adjacent cereal crop. Two idealized situations are considered, taken from the HAPEXMOBILHY examples simulated in section 2. Strongly different atmospheric responses are obtained depending on the soil moisture in the cereal crop area, which suggests that a precise knowledge of the initial soil moisture is required, even with dense vegetation cover, to use advanced evapotranspiration schemes in mesoscale models.

\section{Description of the soil-vegetation scheme}

The surface boundary scheme is a revised version of the soil-vegetation package of Mahfouf et al. (1987a), which was designed for use within mesoscale meteorological models with a grid resolution of about $10 \mathrm{~km}$. Only the modifications are described below.

\footnotetext{
' HAPEX and MOBILHY are acronyms for Hydrologic Atmospheric Pilot EXperiment and MOdélisation du BILan HYdrique.
}

a. Soil

The soil temperature, $T_{s}$, and its volumetric moisture content, $\eta$, are obtained by solving the diffusion equations for heat and moisture fluxes for 13 vertical levels in the first soil meter. The hydraulic conductivity of the soil, $K_{\eta}$, and its hydraulic diffusivity, $D_{\eta}$, are computed as functions of the volumetric moisture content, $\eta$, using the equations of McCumber and Pielke (1981):

$$
\begin{aligned}
K_{\eta} & =K_{\eta s}\left(\frac{\eta}{\eta_{s}}\right)^{2 b+3}, \\
D_{\eta} & =\frac{-b K_{\eta s} \psi_{s}}{\eta}\left(\frac{\eta}{\eta_{s}}\right)^{b+3}, \\
\psi & =\psi_{s}\left(\frac{\eta_{s}}{\eta}\right)^{b}
\end{aligned}
$$

where $\psi$ is the soil moisture potential. A list of symbols is given in the Appendix. The saturated values $\eta_{s}, K_{\eta s}$, $\psi_{s}$ and the exponent $b$ are given by Clapp and Hornberger (1978) for the U.S. Department of Agriculture soil textural classes, but these equations become invalid when the soil is dry to the point where the diffusion of water occurs by means of vapor transport rather than by liquid movements. As the soil water diffusivity for vapor diffusion changes much more slowly than implied by (1)-(3), vapor diffusion has been crudely accounted for by not allowing the diffusivity to drop below $2 \times 10^{-9} \mathrm{~m}^{2} \mathrm{~s}^{-1}$, as suggested by Dickinson (1984).

The thermal conductivity of the soil was obtained from an empirical formula fitted to give reasonable ground heat fluxes on the 12 measurement sites in the HAPEX-MOBILHY area (textural classes ranging from sandy to loamy soils):

$$
\lambda=0.167 \eta+0.1,
$$

where $\lambda$ is the thermal conductivity ( $\mathrm{W} \mathrm{m}^{-1} \mathrm{~K}^{-1}$ ). This formula gives values corresponding to a high organic content according to de Vries (1975), and is in better agreement with the measurements of Kimball et al. (1976) than the expression used by McCumber and Pielke (1981), which seems to overestimate $\lambda$ when the soil is moist.

\section{b. Vegetation}

Mahfouf et al. (1987a) have expressed the fluxes of heat and moisture between the vegetation and the atmosphere using a modified version of the single level canopy model of Deardorff (1978). The foliage temperature is obtained from the solution of a canopy energy budget equation taking into account the exchanges above and below the canopy. The meteorological properties of the air within the canopy are represented by weighting the corresponding values at the ground surface, in the air immediately above, and within the 
vegetation itself. The ground surface temperature and moisture are obtained from a second set of budget equations for the ground level.

The most sensitive parameter in this method is the leaf stomatal resistance, $r_{s t}$, which controls the energy partition between the transpiration flux and the sensible heat flux. The stomatal resistance is affected by many factors, the most prominent of which are the solar radiation and the soil moisture availability. Greatly simplifying the model of Jarvis (1976), we write the stomatal resistance for a representative leaf as the product of three factors:

$$
r_{s t}=r_{s t_{\min }} M_{s t} S_{s t}
$$

where $r_{s t_{\min }}$ is a minimum stomatal resistance, prescribed according to the vegetation type and maturity, $M_{s t}$ is a moisture factor limiting the transpiration rate when water stress occurs, and $S_{s t}$ is the solar radiation factor which decreases $r_{s t}$ from a large value at nighttime to the minimum value $r_{s t_{\min }}$ at noon. We have neglected the dependencies of $r_{s t}$ on the water vapor deficit and on the seasonal temperature included in the Jarvis (1976) model. This effect can be accounted for in the prescription of $r_{s t_{\min }}$ for the short term integrations considered in mesoscale models. It is also worth noting that the definition of $r_{s t}$ refers to a representative leaf. The surface resistance for the whole canopy is taken as 1 / LAI as large as that of a representative leaf, $r_{s t}$, where LAI is the integrated leaf area index of the green leaves. This $1 / \mathrm{LAI}$ correction is approximate and will only work for low values of LAI where little or no shading occurs.

The solar radiation factor of the stomatal resistance equation, $S_{s t}$, is assumed to be of the form given by Dickinson (1984):

$$
S_{s t}=\frac{1+0.0055 R_{s w} \downarrow}{r_{s t_{\min }} / r_{s t_{\max }}+0.0055 R_{s w} \downarrow},
$$

where $r_{s t_{\max }}$ is representative of the resistance of the leaf cuticle (values around $2000 \mathrm{~s} \mathrm{~m}^{-1}$ ), and $R_{s w} \downarrow$ is the time varying downward solar radiation in $\mathrm{W} \mathrm{m}^{-2}$.

Mahfouf et al. (1987a) had related the moisture factor $M_{s t}$ directly to the mean soil volumetric water content in the root area, as suggested by Deardorff (1978). In a preliminary set of tests with HAPEX-MOBILHY data, however, we experienced difficulties of calibration with this technique, the model parameters requiring unacceptably large changes from day to day. Similar problems are reported by Blondin (1987). We have therefore adopted a different approach, which follows more closely the vegetation physiology. Assuming no gain or loss of plant tissue water during the transpiration process, Choudhury and Idso (1985a,b) have shown that the transpiration rate can be computed by equating the rate of soil water extracted by the plant roots to the rate of leaf water extracted by the atmospheric demand. Using their procedure, we evaluate the leaf water potential, $\psi_{f}$, from the simplified soilplant-atmosphere model of Federer (1982):

$$
\psi_{f}=\psi_{s r}-h_{f}-\frac{E_{t r}}{\rho_{w}}\left(R_{f}+R_{r}\right)
$$

and express the moisture factor of the stomatal resistance, $M_{s t}$, using an empirical function of the leaf moisture potential adapted from Choudhury and Idso (1985a):

$$
M_{s t}=1+\left(\frac{\psi_{f}}{\psi_{f c}}\right)^{5.5}
$$

In (7), $\psi_{s r}$ is the average soil moisture potential in the root area, $h_{f}$ the mean canopy height, $E_{t r}$ the transpiration rate, $\rho_{w}$ the density of liquid water, $R_{f}$ the internal resistance to water flow within the plant, and $R_{r}$ the resistance to water flow through the soil to the root surface. The latter term is inversely proportional to the soil hydraulic conductivity, $K_{\eta}$, and is only important as the soil moisture approaches the wilting point. In (8), $\psi_{f c}$ is a critical leaf moisture potential, giving the limit beyond which the transpiration rate is strongly limited by water stress. Its value is usually around -150 $\mathrm{m}$. The exponent value of 5.5 was fitted by Choudhury and Idso (1985a) for wheat, but the simulated evapotranspiration rate is insensitive to the exact form of $M_{s t}$ (Sellers and Dorman, 1987). Values for $h_{f}, R_{f}$, and $\psi_{f c}$ are prescribed according to the vegetation type and maturity, as explained in section 3. Typical values for different types of crops and forests have been given by Federer (1982), Choudhury and Idso (1985b), and Wetzel and Chang (1988).

The formulation presented above provides a feedback limiting the transpiration when the soil becomes very dry or when the atmospheric demand is too strong (e.g., strong wind, dry advection). This feature is desirable for mesoscale studies over heterogeneous terrain. Similar formulations involving the calculation of a leaf moisture potential are used in the SiB (Sellers et al. 1986) and in the BATS (Dickinson 1984).

Finally, the atmospheric resistance of Deardorff (1978), which represents the laminar resistance for the layer between the stomatal openings and the water vapor roughness height, is written

$$
r_{a}=\frac{R e_{c}}{u_{*}},
$$

and is not allowed to increase above $200 \mathrm{~s} \mathrm{~m}^{-1}$ when the friction velocity, $u_{*}$, drops to zero (free convection limit). The definition of $r_{a}$ refers to a representative leaf, as for $r_{s t}$ in (5). A value of 10 is used for the critical Reynolds number, $R e_{c}$. When compared with the expression used by Mahfouf et al. (1987a), (9) predicts foliage temperatures in better agreement with the physiological limit, around $40^{\circ} \mathrm{C}$. This parameterization is based upon the work of Wetzel and Chang (1988). 


\section{Comparison with HAPEX-MOBILHY data}

In this section, data from two cereal crop sites and a forested site of HAPEX-MOBILHY are used for the verification of the soil-vegetation scheme performance. These three examples have been selected to provide strongly contrasted initial conditions in the two-dimensional simulations presented in section 4 .

\section{a. Test sites and available data}

The HAPEX-MOBILHY program was designed to document ground-atmosphere interactions, especially evapotranspiration at a scale of $10^{4} \mathrm{~km}^{2}$. The experimental area, located in southwest France, displays a variety of vegetative and topographic conditions, the most significant contrast being between the $1.410^{4}$ $\mathrm{km}^{2}$ Landes forest to the west, and the rolling hills with mixed agricultural crop to the east. The climate of the area is maritime, relatively humid and mild. From May to July 1986, the project area was heavily instrumented, with networks for meteorological, micrometeorological and soil measurements, local biological monitoring, airborne turbulence and remote sensing measurements. A detailed description of the program implementation can be found in André et al. (1986) and a summary of the first results is given in André et al. (1988a).
For the present study, our interest has been restricted to the micrometeorological, soil and biological data obtained at two agricultural sites and a forested site (listed in Table 1) during two well-documented episodes without rain in mid-June and mid-July.

Both agricultural sites (Tests $\mathrm{C} 1$ and $\mathrm{C} 2$ in Table 1) were instrumented by the French Meteorological Service with automatic micrometeorological stations (André et al. 1986) including a radiation budget meter for both short- and longwave upward and downward components, a net radiometer, and a ground flux-plate. The stations also collected temperature and wind velocity gradients between two levels, and conventional data at screen height. The sensible heat flux was estimated via the flux-gradient relationships and the latent heat flux by balancing the surface energy budget. André et al. (1988a) have found an accuracy of about $20 \%$ for these flux measurements. The local soil water profile was measured by neutron-probe in four access tubes every week. The vegetation height, its LAI, and the vegetation albedo were monitored weekly. Finally, a small number of stomatal resistance and leaf potential measurements were also made using the technique of Taconet et al. (1986).

Test $\mathrm{Cl}$ is performed with data from a maize plot observed from 15 to 18 June. The vegetation is very green and growing rapidly. Its height is about $68 \mathrm{~cm}$.

TABLE 1. Vegetation and soil characteristics for the comparison with HAPEX-MOBILHY data.

\begin{tabular}{|c|c|c|c|c|}
\hline Parameter & Unit & Site $\mathrm{Cl}$ & Site C2 & Site $F$ \\
\hline $\begin{array}{l}\text { Date } \\
\text { Location } \\
\text { Latitude } \\
\text { Longitude } \\
\text { Altitude }\end{array}$ & $\begin{array}{l}\text { deg } \\
\text { deg } \\
\text { m }\end{array}$ & $\begin{array}{l}15-18 \text { June } \\
\text { Lubbon } 2 \\
44^{\circ} 07^{\prime} \mathrm{N} \\
00^{\circ} 03^{\prime} \mathrm{W} \\
146\end{array}$ & $\begin{array}{l}8-11 \text { July } \\
\text { Lubbon } 1 \\
44^{\circ} 07 \mathrm{~N} \\
00^{\circ} 03^{\prime} \mathrm{W} \\
146\end{array}$ & $\begin{array}{l}13-18 \text { June } \\
\text { Estampon } \\
44^{\circ} 05 \mathrm{~N} \\
00^{\circ} 05^{\prime} \mathrm{W} \\
148\end{array}$ \\
\hline \multicolumn{5}{|c|}{ Vegetation } \\
\hline $\begin{array}{l}\text { Vegetation type } \\
\text { Canopy height } \\
\text { Reference height } \\
\text { Canopy albedo } \\
\text { Canopy emissivity } \\
\text { Roughness length } \\
\text { Displacement height } \\
\text { Plant resistance } \\
\text { Minimum stomatal resistance } \\
\text { Critical leaf water potential } \\
\text { Green leaf area index } \\
\text { Dry leaf area index } \\
\text { Shielding factor } \\
\text { Average rooting depth }\end{array}$ & $\begin{array}{l}\mathrm{m} \\
\mathrm{m} \\
\mathrm{m} \\
\mathrm{m} \\
\mathrm{s} \\
\mathrm{s} \mathrm{m}^{-1} \\
\mathrm{~m}\end{array}$ & $\begin{array}{l}\text { Maize } \\
0.68 \\
2 \\
0.17 \\
0.98 \\
0.056 \\
0.51 \\
6.10^{9} \\
50 \\
-100 \\
1.5 \\
0.15 \\
0.8 \\
0.6\end{array}$ & $\begin{array}{l}\text { Oats } \\
\begin{array}{l}1.5 \\
2 \\
0.21 \\
0.98 \\
0.12 \\
1.11 \\
6.10^{9} \\
200 \\
-150 \\
3.0 \\
0.3 \\
0.9 \\
0.6\end{array}\end{array}$ & $\begin{array}{c}\text { Maritime pine } \\
20.3 \\
29 \\
0.10 \\
0.98 \\
1.68 \\
15.2 \\
8.10^{9} \\
350 \\
-150 \\
3.5 \\
0.7 \\
0.85 \\
0.6\end{array}$ \\
\hline \multicolumn{5}{|c|}{ Soil } \\
\hline $\begin{array}{l}\text { Texture } \\
\text { Irrigation } \\
\text { Initial soil moisture } \\
\text { Soil emissivity } \\
\text { Roughness length }\end{array}$ & $\mathrm{m}$ & $\begin{array}{l}\text { Sand } \\
\text { Yes } \\
\quad 0.17 \\
1 \\
0.005\end{array}$ & $\begin{array}{l}\text { Sand } \\
\text { No } \\
\qquad \begin{array}{l}0.08 \\
1 \\
0.005\end{array}\end{array}$ & $\begin{array}{l}\text { Sand } \\
\text { No } \\
\quad \begin{array}{l}0.22 \\
1 \\
0.005\end{array}\end{array}$ \\
\hline
\end{tabular}


The soil is sandy and moist, with a mean volumetric moisture content of 0.17 in the first meter, close to the field capacity for sand [ 0.18 according to Clapp-Hornberger (1978)]. The water table is close to the surface at a depth of $1.3 \mathrm{~m}$ at the time of the test.

Test C2 corresponds to data from an oats plot recorded from 8 to $11 \mathrm{July}$. The oats crop is just ripening, with a height of $1.5 \mathrm{~m}$. The soil is sandy but much drier than in Test $\mathrm{C} 1$. The average volumetric moisture content is only 0.08 , a value close to the wilting point for sand (0.067 according to Clapp-Hornberger 1978). The time evolution of the soil water content in this area, discussed by Andre et al. (1988a), shows that the decrease in water content occurred rather suddenly during the last week of June, and was most significant between 0.4 and $1 \mathrm{~m}$, in the rooting zone.

The forested site (Test $F$ in Table 1) was instrumented primarily by the Institute of Hydrology (U.K.). A full description of the site and observing systems can be found in Gash et al. (1989). Measurements were taken on a $29 \mathrm{~m}$ high tower carrying two automatic weather stations, a radiation instrumentation, and an eddy-correlation system. This latter provided independent average values of evaporation, sensible heat flux and friction velocity from fast response wind, temperature and moisture measurements. Radiometric data included above-canopy solar radiation, net radiation and albedo, and below-canopy net radiation. Monitoring of soil moisture profiles was made weekly using neutron-probe soundings in 12 access tubes. In addition, sap fluxes were estimated on 10 trees and a small number of resistance and water potential measurements were performed on pine needles.

The data for Test $F$ were collected in the northeast part of the Landes forest from 13 to 18 June. The vegetation at and around the measurement site is a sparse maritime pine stand with a well-developed bracken understory. The tree average height is $20.3 \mathrm{~m}$ and the density is around 430 stems per hectare. An important feature of this sparse forest, emphasized by Gash et al. (1989), is that more than $30 \%$ of the above canopy radiation reaches the undergrowth, resulting in a much larger contribution from the bracken to the transpiration than under normal midlatitude forest conditions. The soil is sandy, overlying a deeper layer of clay. This site is therefore unusual in that although located on what would normally be a well-drained soil, the water table is close to the surface and the moisture content close to saturation, with a value of 0.22 at the time of the test. Consequently, the average rooting depth is estimated as $0.6 \mathrm{~m}$, a value comparable to that used for Sites $\mathrm{C} 1$ and $\mathrm{C} 2$.

\section{b. Evaluation of the model performance}

In this subsection, we describe the results of the simulations made at the three test sites and compare with the observations. The soil-vegetation scheme is used in a stand-alone mode and driven directly by the observations of wind, temperature, moisture and downward radiations made at the reference level above the canopy. The observed downward longwave radiation is obtained from the difference between the total and solar downward fluxes for Sites $\mathrm{C} 1$ and $\mathrm{C} 2$, and estimated from nearby stations for Site F. All simulations are started at midnight, local time. The foliage and ground temperatures are initialized with the measured air temperatures at the reference height. The soil moisture profiles are initialized uniformly with the average moisture content in the first meter taken from the neutron-probe observations.

The biological and physical characteristics for the vegetation are prescribed as shown in Table 1 . Observations were available to set values for the vegetation height and albedo. The soil albedo is given as a function of the surface soil moisture (Mahfouf et al. 1987a). The roughness length and displacement height were estimated using standard formulas as $8 \%$ and $75 \%$ of the vegetation height (Thom et al. 1975; and Jarvis 1976). Observations suggest that the $8 \%$ ratio slightly underestimates the roughness for Site F (9.3\%; Gash et al. 1989). The plant resistance, $R_{f}$ in (7), is expressed using the observational results of Katerji (1982) for an alfalfa crop:

$$
R_{f}=\frac{R_{f 0}}{\left(1+0.006 R_{n}\right)}
$$

where $R_{n}$ is the net radiation. The value of the constant $R_{f 0}$ has been derived from the data of Denmead (1976) for cereals (Sites C1 and C2), and Federer (1982) for forest (Site F). The prescription of the minimum stomatal resistance, $r_{s t_{\min }}$, and of the critical leaf water potential, $\psi_{f c}$, must be done very carefully since these parameters are the most sensitive factors affecting the energy partition between sensible and latent heat fluxes. For green growing cereals (Site C1), the data of Denmead (1976) and those of Choudhury and Idso (1985b) suggest values around $50 \mathrm{~s} \mathrm{~m}^{-1}$ for $r_{s t_{\min }}$ and $-100 \mathrm{~m}$ for $\psi_{f c}$. For mature ripening cereals (Site C2), the observations of Taconet et al. (1986) give larger values for $r_{s t_{\min }}$, around $200 \mathrm{~s} \mathrm{~m}^{-1}$. For a conifer forest (Site $F$ ), the $r_{s t_{\min }}$ and $\psi_{f_{c}}$ values are estimated from direct measurements on pine needles for a small number of trees. The LAI was measured for Site $\mathrm{Cl}$, and empirically derived from the vegetation height for Site $\mathrm{C} 2$. The selected LAI for Site F is a global value for the upper pine canopy and the bracken understory; Gash et al. (1989) report a value of 2.3 for the upper canopy only. The shielding factor, $\sigma_{f}$, (Deardorff 1978 ) is the percentage of direct solar radiation intercepted by the canopy at noon; this quantity was not measured, and was obtained from the simulations by trial and error. Sensivity tests have shown that changing $\sigma_{f}$ by $\pm 15 \%$ modifies the latent and sensible heat fluxes of about $\pm 20 \%$. 
DATA
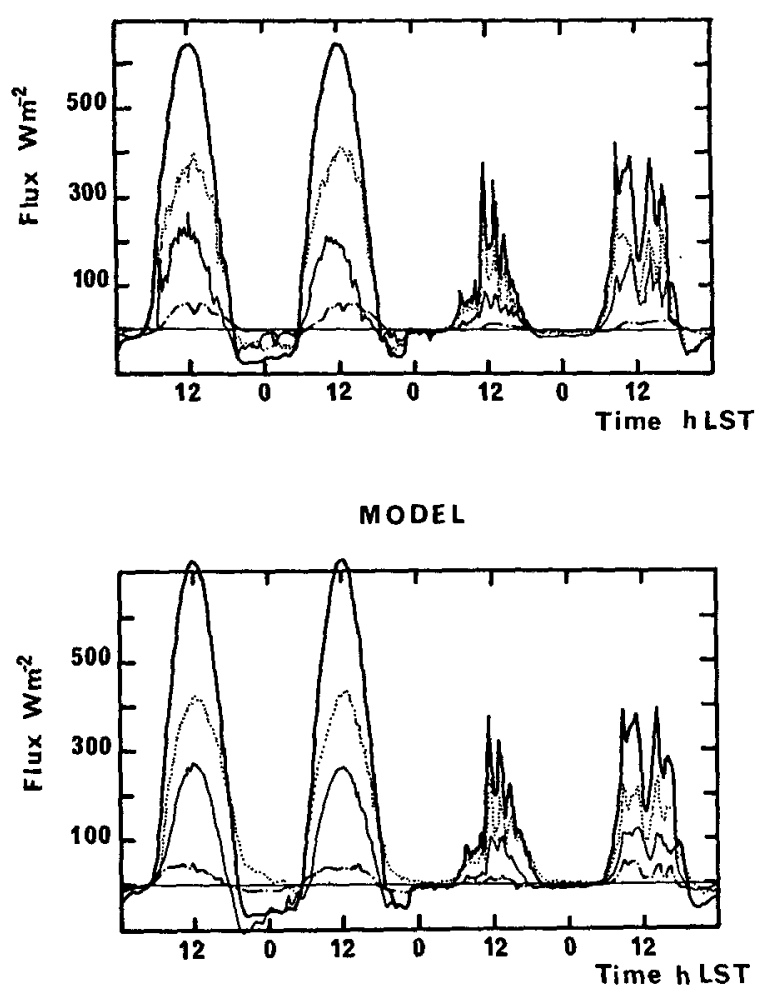

FIG. 1. Observed and predicted values $\left(\mathrm{W} \mathrm{m}^{-2}\right)$ of net radiation (heavy solid line), latent heat flux (dotted line), sensible heat flux (light solid line), and ground heat flux (dotted-dashed line) for a green maize crop, Site C1, 15-18 June 1986.

\section{1) SITE C1: GROWING MAIZE OVER MOIST SOIL}

The model computations are made using the observed meteorological variables sampled every $15 \mathrm{~min}$ utes at $2 \mathrm{~m}$ above the ground surface. Figure 1 shows the observed and simulated time series for the net radiation, latent heat flux, sensible heat flux, and ground heat flux. The predicted fluxes and the observations generally agree well. During the first two days when the sky is clear, the predicted and observed Bowen ratios, $H / \mathrm{LE}$, are around 0.5 , as expected for green growing vegetation over moist soil. During the last two days, changes in the cloud cover result in sharp flux variations which are qualitatively well recovered by the model. The most noticeable difference between the predictions and the observations is an overestimation of the latent heat flux during the evening and at night. This difference seems to originate in an overestimation of the soil evaporation. Figure 2 shows a direct comparison of the observed and predicted flux values, for the period corresponding to the time series of Fig. 1. The sampling rate is one value per hour. The standard deviation of the difference between observations and predictions is around $30 \mathrm{~W} \mathrm{~m}^{-2}$, with a smaller scatter for net radiation. The overestimation of the large values of the net radiation could result from an underestimated foliage temperature or from uncertainties in the surface albedo and emissivity.
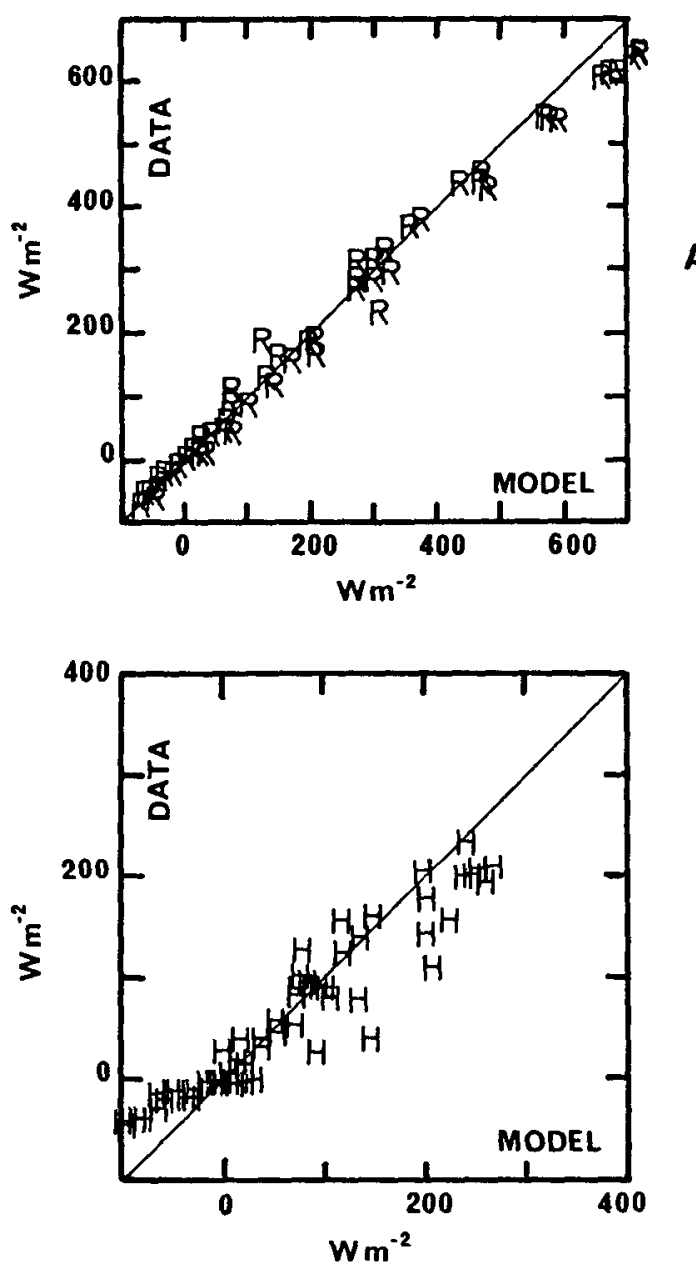

B

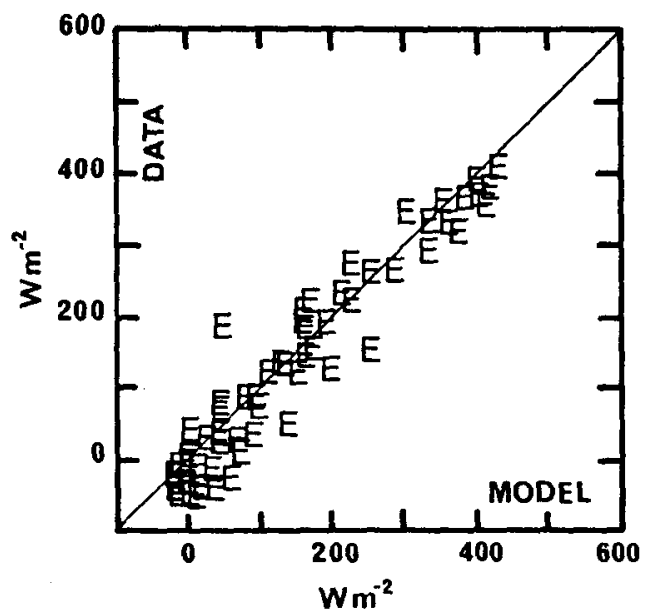

FIG. 2. Comparison of observed and predicted values $\left(\mathrm{W} \mathrm{m}^{-2}\right)$ of net radiation (A), sensible heat flux (B), and latent heat flux (C), for a green maize crop, Site C1, 15-18 June 1986. 
Figure 3a shows the time evolutions of the predicted soil moisture potential and leaf water potential. Since the soil is moist, the soil moisture potential is close to zero during the four simulated days. The leaf water potential oscillates between a maximum value close to the soil moisture potential at night, and a minimum smaller than $-150 \mathrm{~m}$ during the afternoon on sunny days. Equivalent results were obtained by Sellers and Dorman (1987) using the $\mathrm{SiB}$ model over a growing barley crop. Figure $3 \mathrm{~b}$ shows the predicted stomatal resistance for the same days. The stomatal resistance approaches its light-limited $r_{s t_{\min }}$ value early in the morning and then increases during the day as the evaporative demand rises and the leaf potential falls. The shaded area in Fig. $3 \mathrm{~b}$ shows the range of the stomatal resistances measured with a diffusion porometer on the site during the afternoon of 16 June. The predicted resistance provides a reasonable match with the observations; this agreement could, however, be coincidental due to the variability and uncertainty of such measurements. It should also be noted that the afternoon value of the stomatal resistance-and of the transpiration-is controlled directly by the moisture flux into the root system and not by the atmospheric demand, since the leaf water potential is significantly
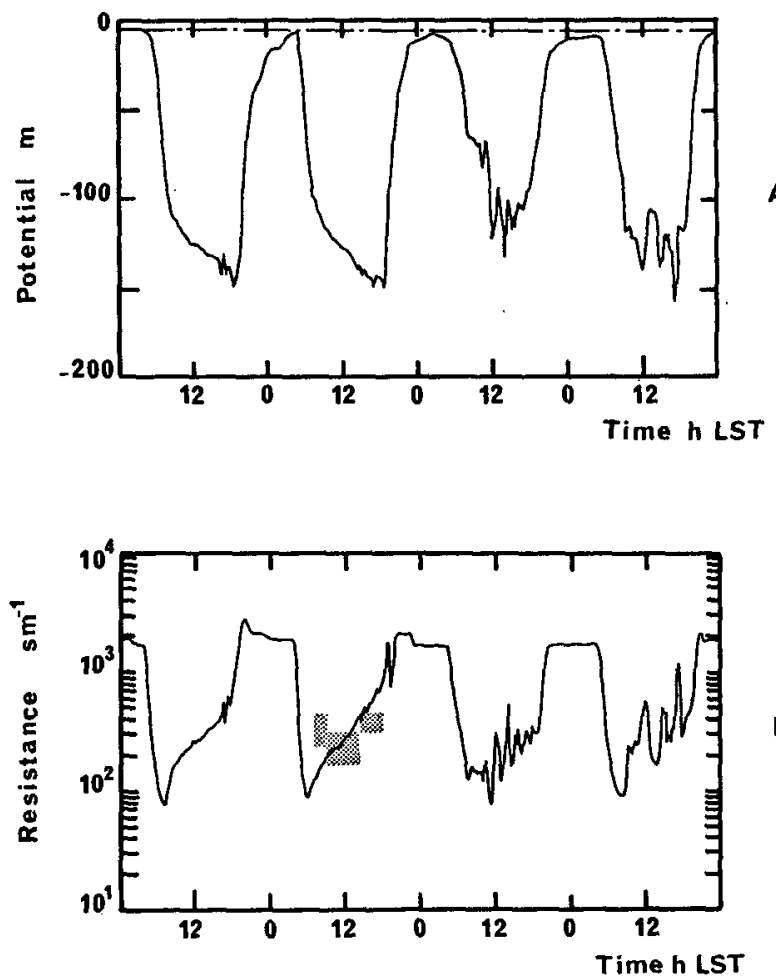

FIG. 3. Predicted time variations of leaf water potential (A, solid line, $m$ ), average soil moisture potential in the rooting zone $(A$, dotted-dashed line, $\mathrm{m}$ ), and stomatal resistance (B, solid line, $\mathrm{s} \mathrm{m}^{-1}$ ) for a green maize crop, Site C1, 15-18 June 1986. The shaded area in (B) indicates the range of the stomatal resistance measurements (data CNET/CRPE). lower than the critical leaf potential value $\left(\psi_{f c}=-100\right.$ $\mathrm{m}$ ) during the afternoon. This result, obtained for a moist soil but with a strong atmospheric demand supports the conclusions of Wetzel and Chang (1984), who emphasize the importance of root control in transpiration.

\section{2) SITE C2: MATURE OATS OVER DRY SOIL}

This example is similar to the first one in many respects, except that the vegetation is just ripening and the soil is dry. Figure 4 shows the observed and predicted time evolutions of the net radiation, sensible heat flux, latent heat flux, and ground heat flux. Observed sensible and latent heat fluxes are missing during the evening on 8 and $9 \mathrm{July}$, because of anemometer problems. The model provides a good general prediction of the observed fluxes. In contrast with the first example, most of the available energy is exchanged through sensible heat, giving a Bowen ratio larger than 3. A more quantitative view of the model behavior is given in Fig. 5, which shows a direct comparison of the observed and predicted flux values for the four simulated days. A standard deviation close to $30 \mathrm{~W}$ $\mathrm{m}^{-2}$ is found, as in the first simulation. The larger deviations on the sensible heat flux diagram for the negative predicted fluxes correspond to the missing data in Fig. 4.

The very small values found for the evapotranspiration are due to the cumulative effects of (i) the increased $r_{s t_{\min }}$ value for ripening oats, and (ii) the significant water stress. The importance of this latter effect can be seen in Fig. 6, where the soil moisture potential and the leaf water potential are displayed. The soil moisture potential is rather low, close to $-100 \mathrm{~m}$ (corresponding to an initial moisture content of $45 \%$ of the field capacity), and it is slowly decreasing because of root water extraction. The leaf water potential falls around $-200 \mathrm{~m}$ in the afternoon, reaching values much lower than the critical leaf moisture potential $\left(\psi_{f c}\right.$ $=-150 \mathrm{~m}$ ), and therefore strongly limiting the transpiration through (8).

\section{3) SITE F: CONIFER FOREST OVER MOIST SOIL}

For this site the computations are made using observed meteorological variables at $29 \mathrm{~m}$ above the ground surface every hour. Figure 7 shows the observed and predicted time series of the net radiation, sensible heat flux, and latent heat flux. The ground heat flux was not observed, and only its predicted values are shown in the lower panel. The model gives a fair description of the data, especially with respect to the different influence of the forest on the energy balance. Despite the high roughness of the forest, the evapotranspiration is reduced by the relatively high stomatal resistance (Fig. 9a). Accordingly, the Bowen ratio is very close to unity, in spite of the high soil moisture 
DATA

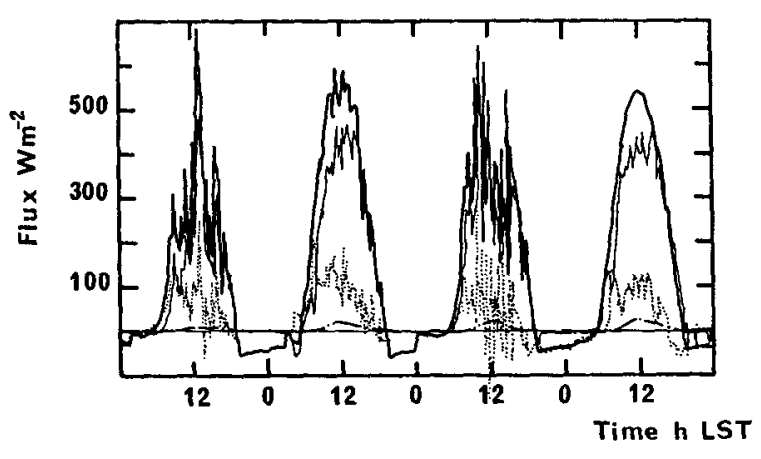

MODEL

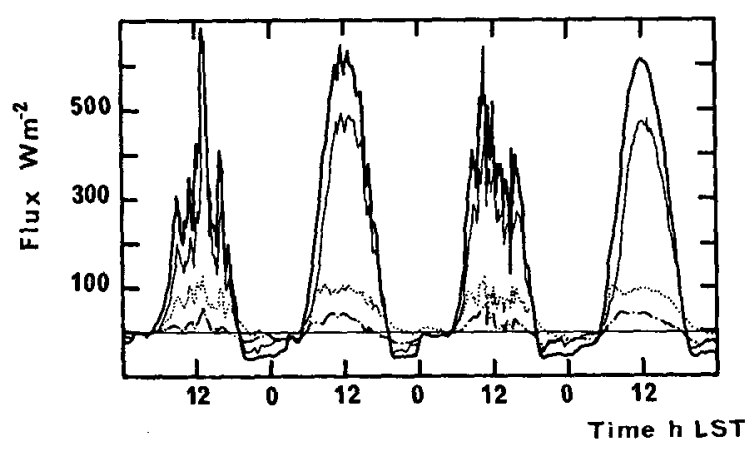

FIG. 4. Observed and predicted values $\left(\mathrm{W} \mathrm{m}^{-2}\right)$ of net radiation (heavy solid line), latent heat flux (dotted line), sensible heat flux (light solid line), and ground heat flux (dotted-dashed line) for a mature oats crop, Site C2, 7-11 July 1986.

availability. When compared with the cereal crop of Site $\mathrm{C} 1$, the forest of Site F appears to be associated with a significantly larger sensible heat flux, and this has important consequences investigated in the next section. Figure 8 shows the observed values of the fluxes plotted against the predicted ones for the same days as in Fig. 7. The scatter is slightly larger than for the previous examples, with a standard deviation around 35 $\mathrm{W} \mathrm{m}^{-2}$ for the sensible and latent heat fluxes.

The time evolution of the leaf water potential is plotted in Fig. 9b. In spite of the very small value of the soil moisture potential, the leaf water potential falls to less than $-150 \mathrm{~m}$, because of the large plant resistance, $R_{f}$, in (7). This leaf water potential is too high to substantially increase the stomatal resistance, however, and the transpiration rate is mostly controlled by the atmospheric demand. Gash et al. (1989) have measured the average diurnal evolution between 10 June and 22 July of the surface resistance for the same site. When corrected for the measured LAI of the pine canopy $(\mathrm{LAI}=2.3)$, their stomatal resistance values are $40 \%$ smaller than the predicted values of Fig. 9a. The origin of this difference probably lies in the different assumptions made to represent the vegetation's understory. Gash et al. (1989) have not considered the role of the bracken understory in evaluating the surface resistance. In contrast, we assume that our single canopy model accounts for both stories upper and lower

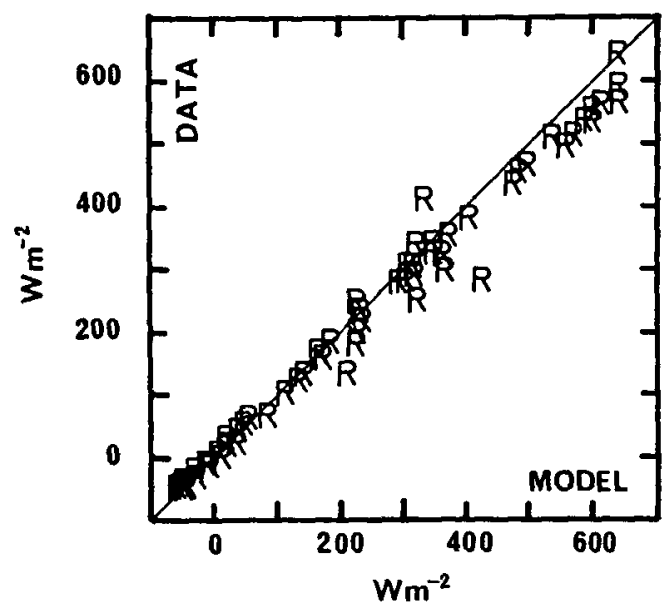

A

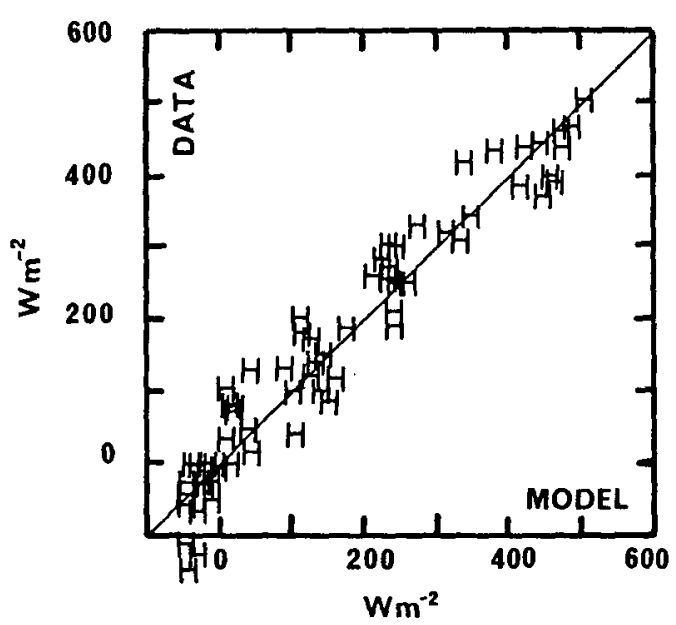

B

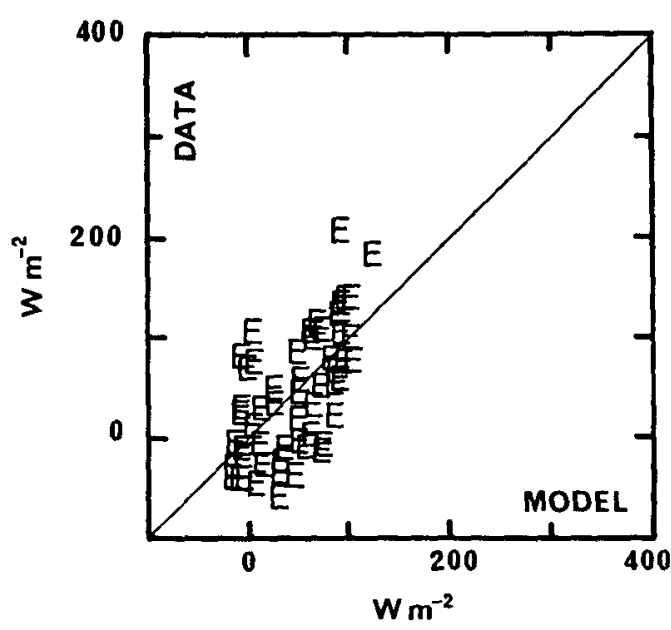

FIG. 5. Comparison of observed and predicted values $\left(\mathrm{W} \mathrm{m}^{-2}\right)$ of net radiation (A), sensible heat flux (B), and latent heat flux (C), for a mature oats crop. Site C2, 7-11 July 1986. 


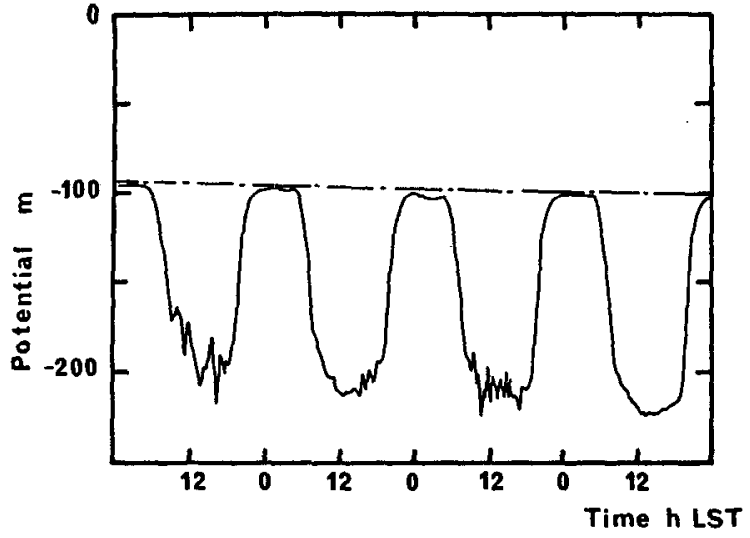

Fig. 6. Predicted time variations of leaf water potential (solid line, $\mathrm{m}$ ), and average soil moisture potential in the rooting zone (dotteddashed line, m), for a mature oats crop, Site C2, 7-11 July 1986.

of the vegetation by prescribing a LAI of 3.5 (2.3 for the pine canopy, and 1.2 for the bracken understory).

In summary, for the limited set of three examples considered in the present study, the soil-vegetation scheme appears to simulate accurately the energy partition between sensible and latent heat fluxes. When modeling local scale processes (few $\mathrm{km}^{2}$ ) or homoge- neous conditions, the previous discussion shows that the uncertainties in prescribed parameters and the simplifications of biophysical processes lead to errors of about $\pm 50 \mathrm{~W} \mathrm{~m}^{-2}$. It should be noted, however, that further tests involving a more comprehensive set of vegetation types and sensitivity tests are required before drawing a general conclusion.

\section{Atmospheric response to two-dimensional vegeta- tion heterogeneities}

In this section, we use the soil-vegetation package of section 2 to study an idealized two-dimensional situation in which an atmospheric circulation develops in response to the thermal contrasts between a forest and an adjacent agricultural crop on a horizontal scale of about $200 \mathrm{~km}$.

\section{a. Description of the atmospheric model}

The atmospheric model is a two-dimensional version of the hydrostatic primitive equation model of Nickerson et al. (1986) which was adapted, as explained in detail by Mahfouf et al. (1987a,b), to make it more suitable for land-surface process studies. These modifications include (i) an improved description of the

DATA

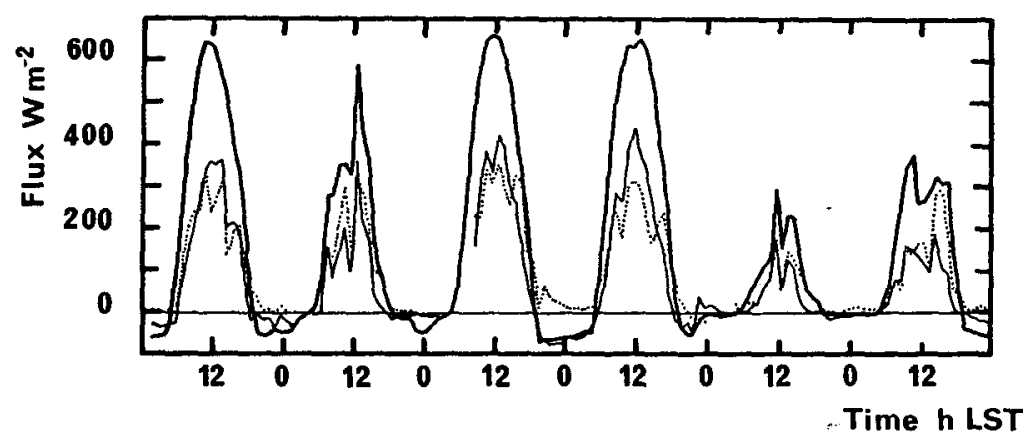

MODEL

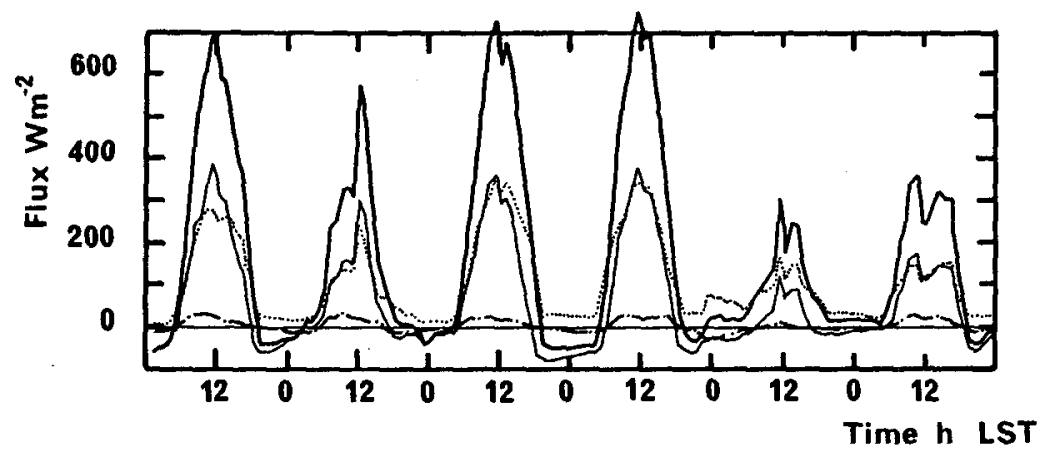

FIG. 7. Observed and predicted values $\left(\mathrm{W} \mathrm{m}^{-2}\right.$ ) of net radiation (heavy solid line), latent heat flux (dotted line), sensible heat flux (light solid line), and ground heat flux (model only, dotted-dashed' line) for the Landes forest, Site F, 13-18 June 1986. 


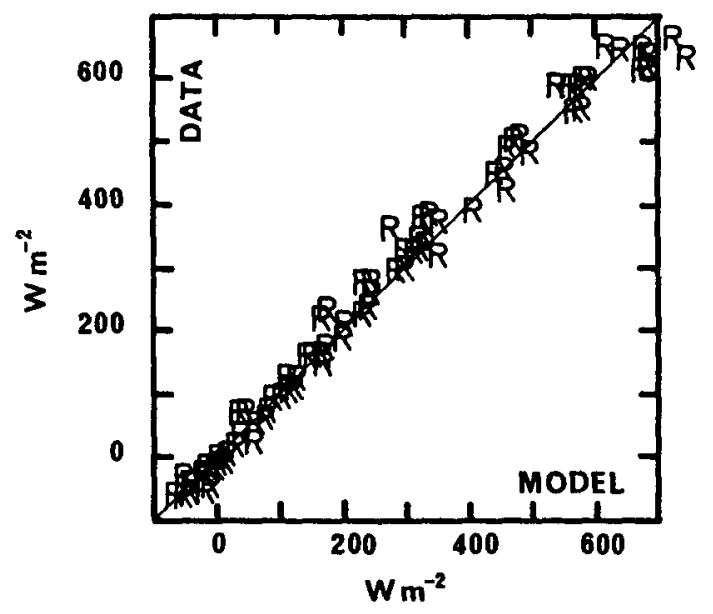

by Mahfouf et al. (1987a) was replaced by the scheme described in section 2 and calibrated against HAPEXMOBILHY data in section 3.

\section{b. Initial conditions of the numerical experiments}

A

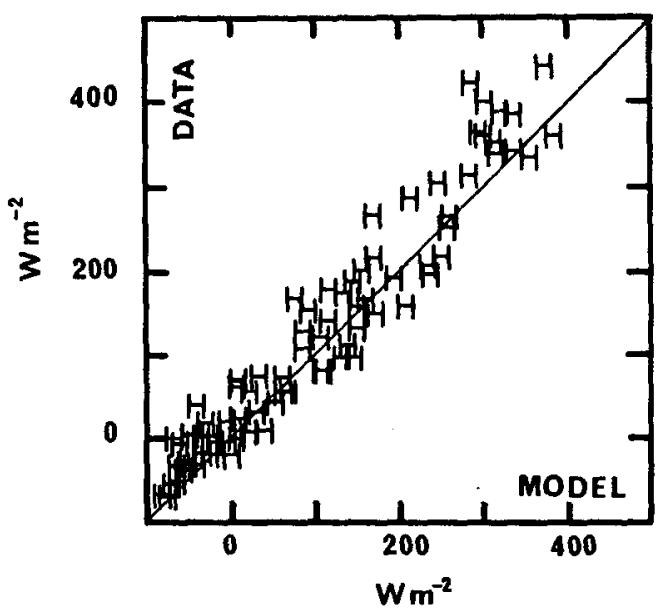

As the aim of the paper is to provide some rationale for discussing the effects of different surface conditions, this study is restricted to the very simple case-already used by Mahfouf et al. (1987a) - of a two-dimensional flow over flat terrain in the absence of all other atmospheric forcing which would mask the circulations driven by variations in surface properties. The initial wind is therefore set to zero, no synoptic flow occurs and the Coriolis force is neglected. The recent results of Yan and Anthes (1987) indicate that this convenient simplification is acceptable for short term integrations (i.e., first $12 \mathrm{~h}$ ) during the hours of strong heating, even for midlatitudes. For longer term integrations, however, the Coriolis term becomes dominant (except at the equator) and should be accounted for. The model contains 15 levels, 7 of which are located below $2 \mathrm{~km}$, allowing a high resolution of the PBL. The model top height is approximately $14 \mathrm{~km}$. The horizontal domain size is $420 \mathrm{~km}$ wide, with a uniform grid length of 10 $\mathrm{km}$. The lateral conditions are open, with a damping zone (width $90 \mathrm{~km}$ ) on both sides to prevent spurious reflexions into the model. The time step is $10 \mathrm{~s}$. The model is initialized at 0600 LST using clear sky vertical profiles for potential temperature and water mixing ratio typical of the HAPEX-MOBILHY area for midJune. These profiles are shown in Fig. 10. The astronomical parameters for radiation correspond to 16 June at a latitude of $44^{\circ} \mathrm{N}$ (HAPEX-MOBILHY area).

Two numerical experiments are performed with different soil moisture, but identical vegetation and atmospheric conditions, as summarized in Table 2. For each experiment, the land surface is separated horizontally into two distinct zones: the western half of the domain (zone A) is covered with a typical cereal crop, whereas the eastern half (zone B) is covered with a typical conifer forest. In both zones, the vegetation and soil characteristics are taken from the results obtained in section 3 for the HAPEX-MOBILHY sites. To prevent numerical noise, the border between the two vegetation zones is smoothed by inserting a transition zone consisting of two points with parameters prescribed as weighted $(0.33,0.67)$ averages of zone A-B values.

\section{c. Experiment 1: cereal/forest transition over moist soil}

FIG. 8. Comparison of observed and predicted values $\left(\mathrm{W} \mathrm{m}^{-2}\right)$ of net radiation (A), sensible heat flux (B), and latent heat flux (C), for the Landes forest, Site F, 13-18 June 1986.

PBL using a prognostic turbulent kinetic energy equation and (ii) a clear sky radiation parameterization. For the present study, the soil-vegetation scheme used

In the first experiment, we consider the circulation produced when the soil water is readily available for both the agricultural crop on the western side (zone A) and the forest on the eastern side (zone B). The vegetation characteristics for zone $A$ are taken from Site $\mathrm{Cl}$ of Table 1 (green cereal growing over moist 

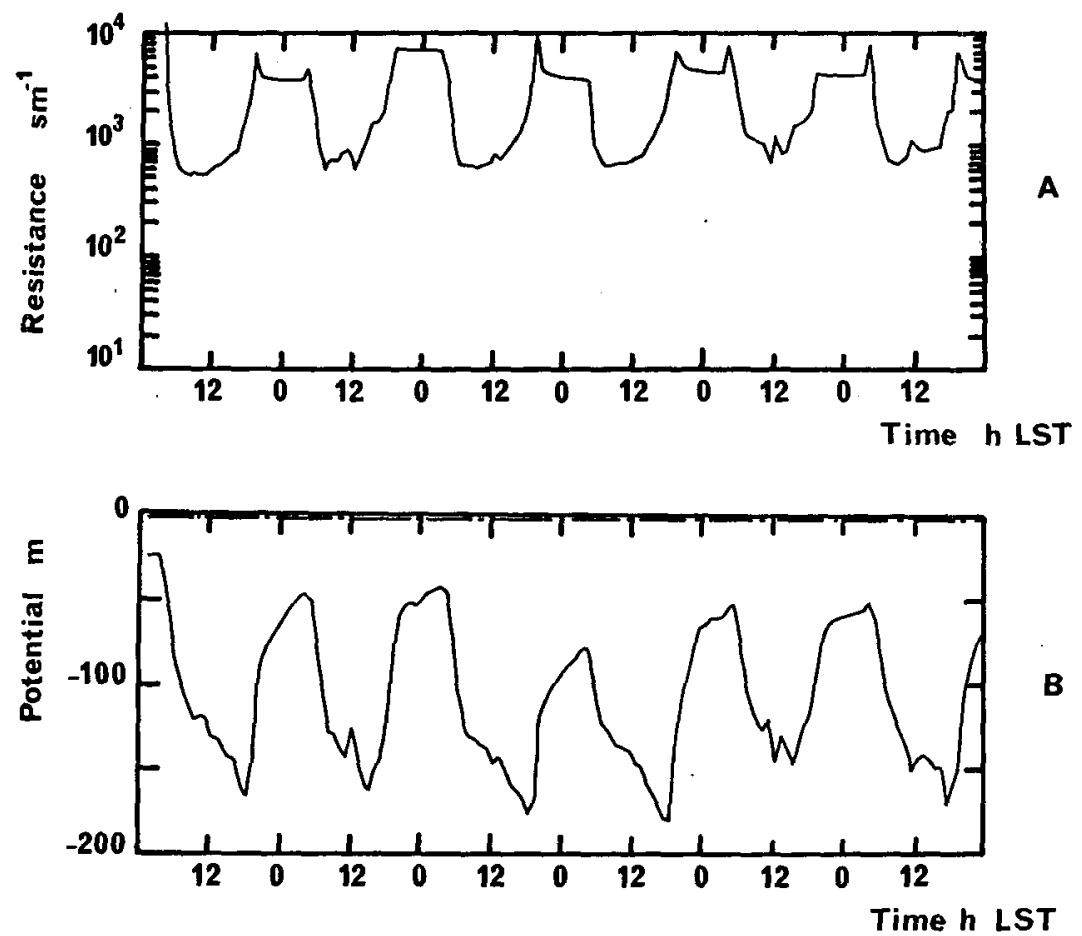

Fig. 9. Predicted time variations of stomatal resistance (A, solid line, $\mathrm{s} \mathrm{m}^{-1}$ ), leaf water potential ( $B$, solid line, $m$ ), and average soil moisture potential in the rooting zone ( $B$, dotted-dashed line, $m$ ), for the Landes forest, Site F, 13-18 June 1986.

soil), those for zone B are obtained from Site F (conifer forest over moist soil). A preliminary analysis of this experiment is also reported in André et al. (1989).

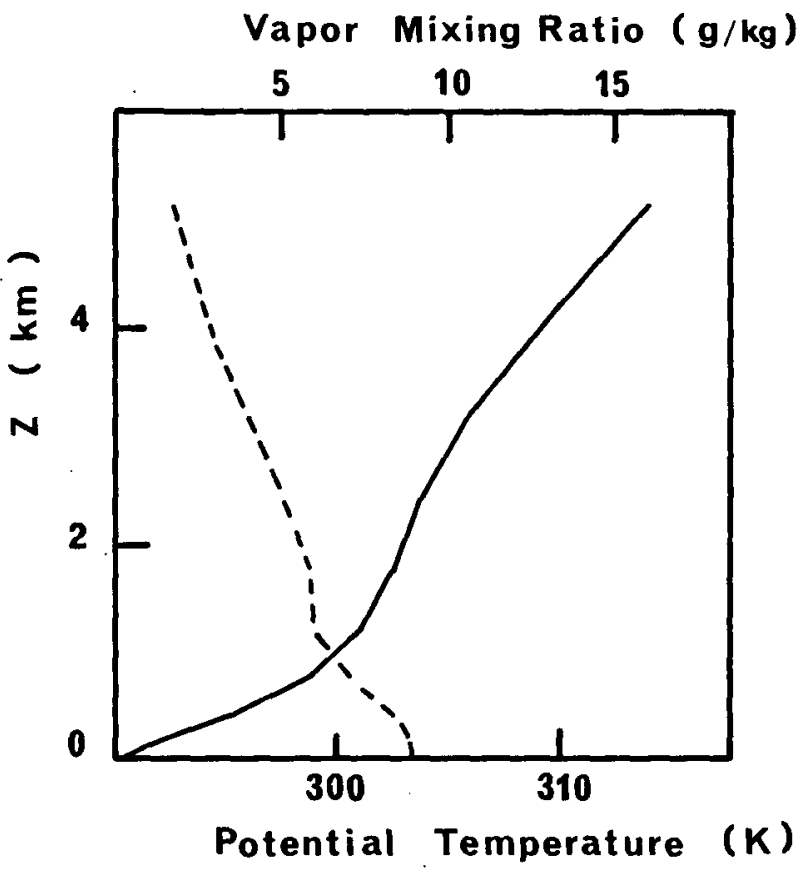

FIG. 10. Initial profiles for potential temperature (solid line, $\mathrm{K}$ ), and water vapor mixing ratio (dashed line, $\mathrm{g} \mathrm{kg}^{-1}$ ).
Figure 11 shows the variations of the latent and sensible heat fluxes across the model domain at 1500 LST. We first remark that, except near the boundary between the two vegetation zones, the Bowen ratios are closely consistent with the results of section 3-values close to 0.5 over the cereal and equal to 1 over the forest. This response reflects the above-mentioned differences in stomatal resistance between the forest and the cereal crop. Furthermore, due to reduced albedo and slightly different foliage temperature, the available surface energy is larger over the forest than over the cereal crop, leading to a larger total heat flux $(H+L E)$. This results in a stronger sensible heat exchange over the forest than over the cereals, giving an average difference of about $100 \mathrm{~W} \mathrm{~m}^{-2}$ across the discontinuity, with slightly larger values in the transition region between the two vegetation zones. On the other hand, the latent heat flux is nearly constant across the domain with values close to $300 \mathrm{~W} \mathrm{~m}^{-2}$. This nearly homogeneous latent heat flux distribution is probably coincidental, since

TABLE 2. Summary of the experiments.

\begin{tabular}{ccll}
\hline Experiment & Zone & Vegetation & \multicolumn{1}{c}{ Soil } \\
\hline 1 & A & Cereal crop & Moist sand \\
& B & Conifer forest & Moist sand \\
2 & A & Cereal crop & Dry sand \\
& B & Conifer forest & Moist sand \\
\hline
\end{tabular}




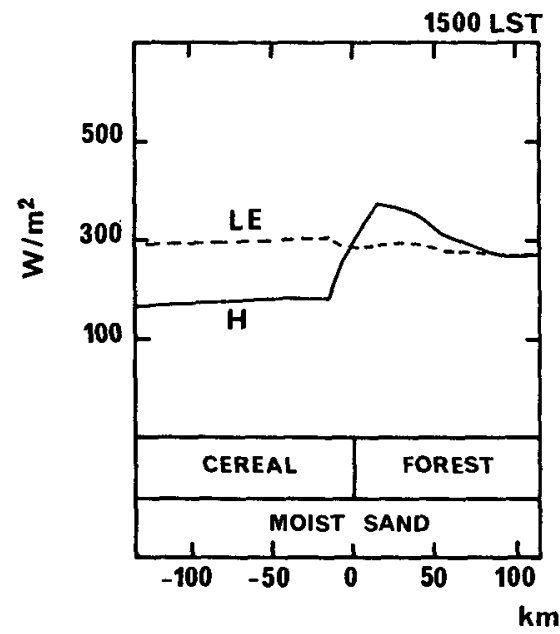

FIG. 11. Horizontal profiles of surface sensible (solid line) and latent (dashed line) heat fluxes $\left(\mathrm{W} \mathrm{m}^{-2}\right)$ at 1500 LST for Experiment 1.

more significant variations were obtained in further tests.

The atmospheric response to the sensible heat flux distribution is shown in Figs. 12 and 13, which respectively display the cross sections of the horizontal and vertical velocity fields at 1800 LST. A "forest-

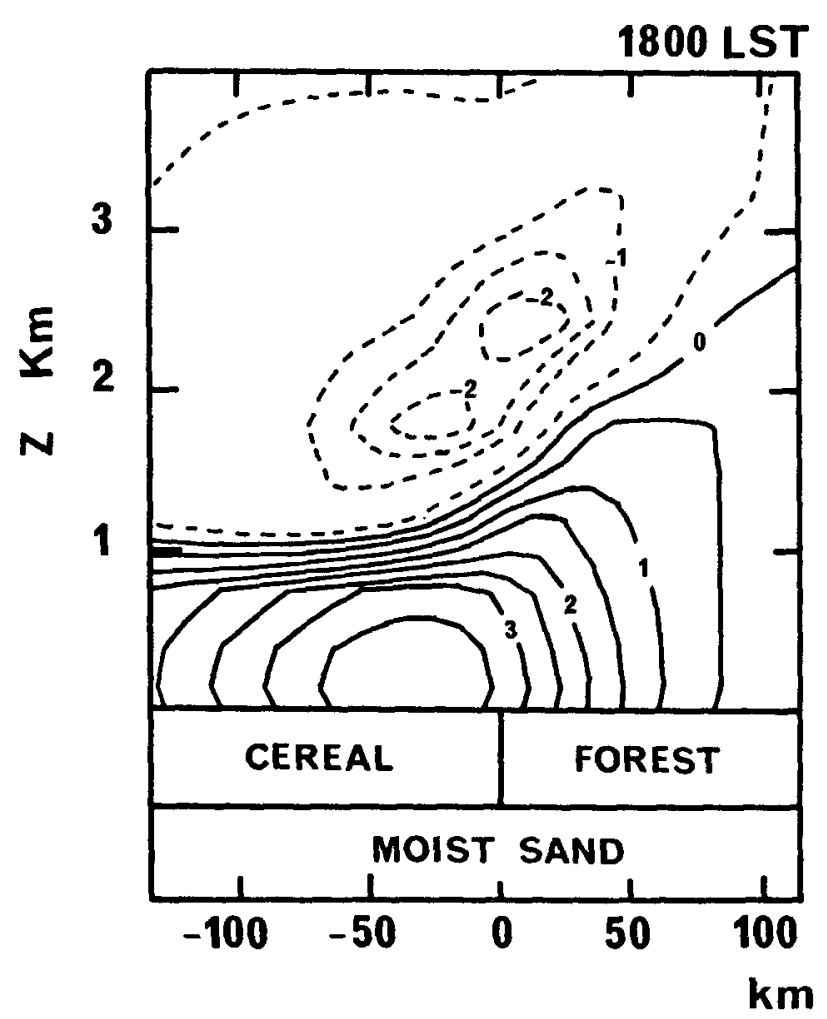

FIG. 12. Vertical cross section of horizontal wind speed $\left(\mathrm{m} \mathrm{s}^{-1}\right)$ at 1800 LST for Experiment 1. breeze" circulation develops, with horizontal winds of about $4 \mathrm{~m} \mathrm{~s}^{-1}$ blowing toward the forest in the lowest kilometer, and a weaker return flow aloft. This horizontal wind is associated with a $5 \mathrm{~cm} \mathrm{~s}^{-1}$ ascending motion above the forest and a weaker descending cell over the cereal zone, forming a closed circulation analogous to a classic sea-breeze flow (for instance, see Yan and Anthes 1987). Contrasting with the sea-breeze circulation, however, the forest breeze shows no significant sign of breeze front penetration into the forested zone. This absence of flow propagation into the heated zone is probably due to the smaller air temperature difference across the domain than in the case of classic sea breeze, as suggested by the analysis of Physik ( 1980 , p. 742) and Simpson et al. (1977).

The vertical cross section of the turbulent kinetic energy computed by the model at 1500 LST is shown in Fig. 14. Three processes are cooperating to modify the intensity of the turbulence and the depth of the PBL: (i) the larger roughness length increases the low level turbulent production over the forest; (ii) the larger amount of sensible heating over the forest gives rise to a deeper and more turbulent PBL in zone B; (iii) near the boundary zone, the turbulent shear production is increased by the shear of the mesoscale wind (Fig. 15) and the mesoscale ascending motion favors the transport of turbulence upwards.

The cross sections of the potential temperature and

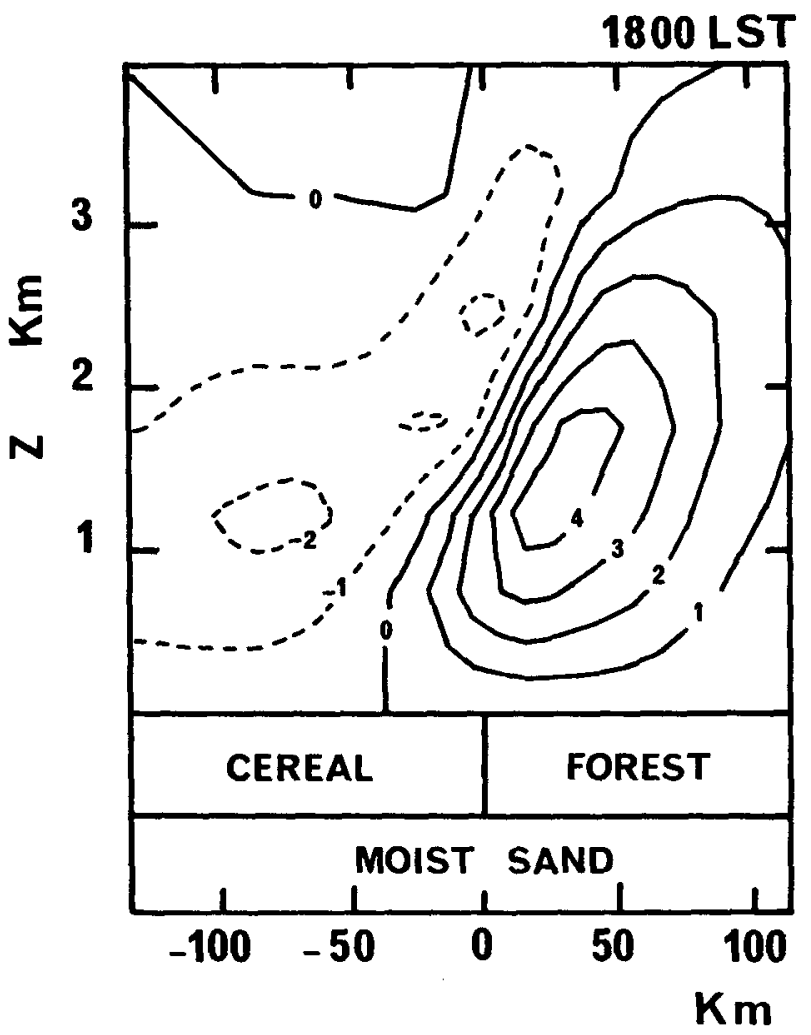

FIG. 13. Vertical cross section of vertical velocity $\left(\mathrm{cm} \mathrm{s}^{-1}\right)$ at 1800 LST for Experiment 1. 


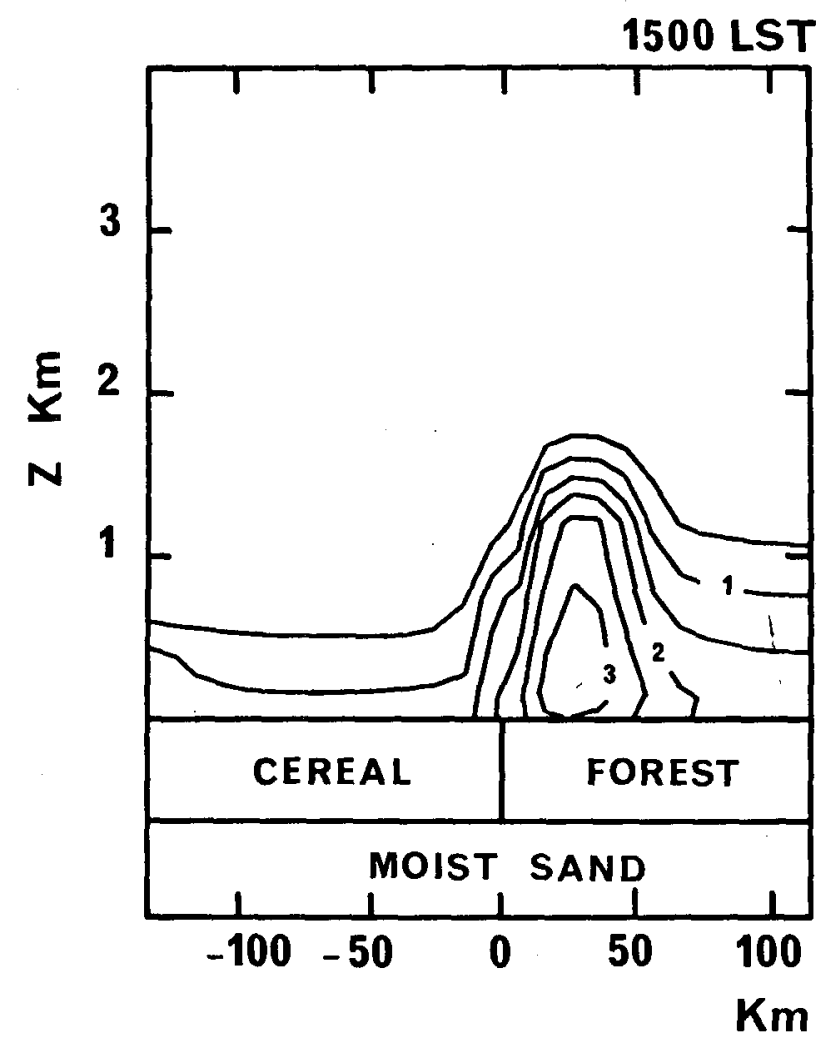

FIG. 14. Vertical cross section of turbulent kinetic energy $\left(\mathrm{m}^{2} \mathrm{~s}^{-2}\right)$ at 1500 LST for Experiment 1.

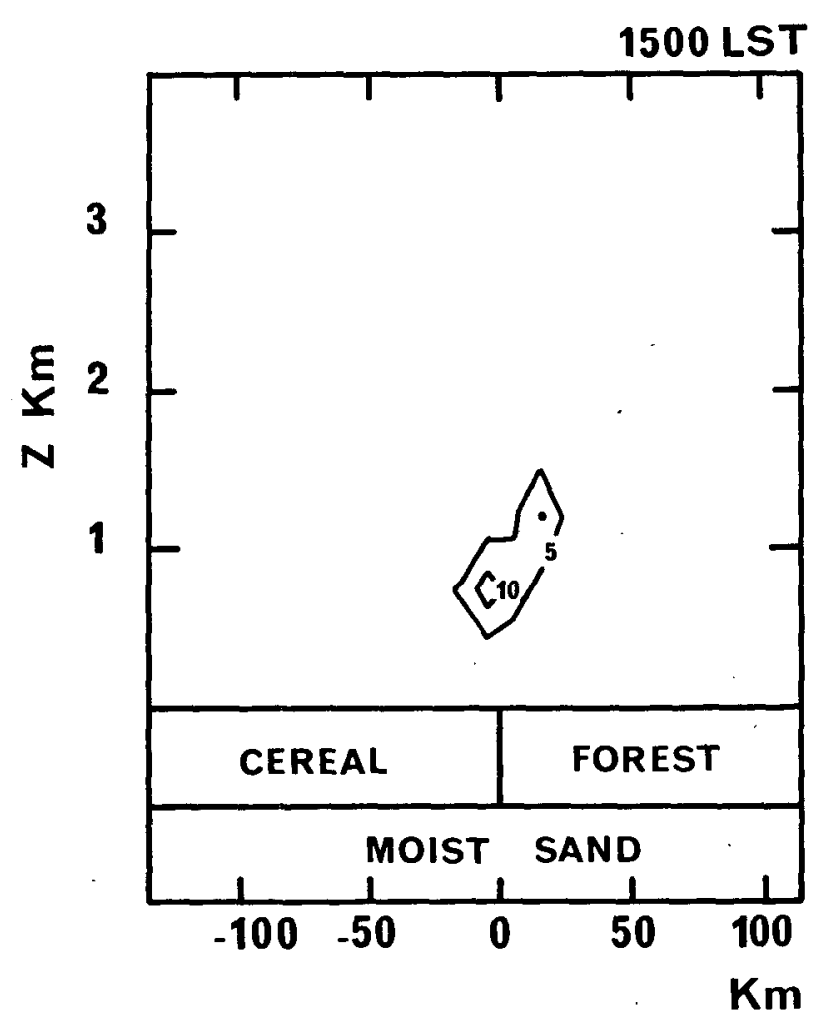

FIG. 15. Vertical cross section of shear production of turbulent kinetic energy $\left(\mathrm{cm}^{2} \mathrm{~s}^{-3}\right)$ at 1500 LST for Experiment 1. water vapor mixing are respectively shown in Figs. 16 and 17. Both of these fields closely follow the distribution of the turbulence intensity. Over the forest, the mixed layer grows deeper and warmer, reflecting the larger sensible heat flux at the surface. The PBL depth is close to $2 \mathrm{~km}$ over the forest, and $1 \mathrm{~km}$ over the cereals. Owing to the nearly uniform surface moisture flux, the PBL is drier over the forest since the same amount of water is mixed over a deeper layer. Furthermore, in the upper part of the forest PBL-around $1.5 \mathrm{~km}$ above the ground-the maximum of the moisture field closely corresponds to the maximum of the ascending motion (Fig. 13) and to a significantly turbulent region (Fig. 14).

The boundary zone between the cereals and the forest could therefore be a preferential location for the initiation of clouds, if the local meteorological environment were appropriate. This assumption is further strengthened by comparing the intensity of the forestbreeze circulation to other examples of flows driven by differential surface heating. Table 3 lists the maximum horizontal wind in the PBL computed for several examples of classic sea-breeze and "inland sea-breeze" [circulations produced by soil moisture variations; Yan and Anthes (1988)]. The results of Ookouchi et al. (1984) and Yan and Anthes (1988) were obtained with nearly the same soil conditions, but only the model of Yan and Anthes (1988) included cloud and rain for-

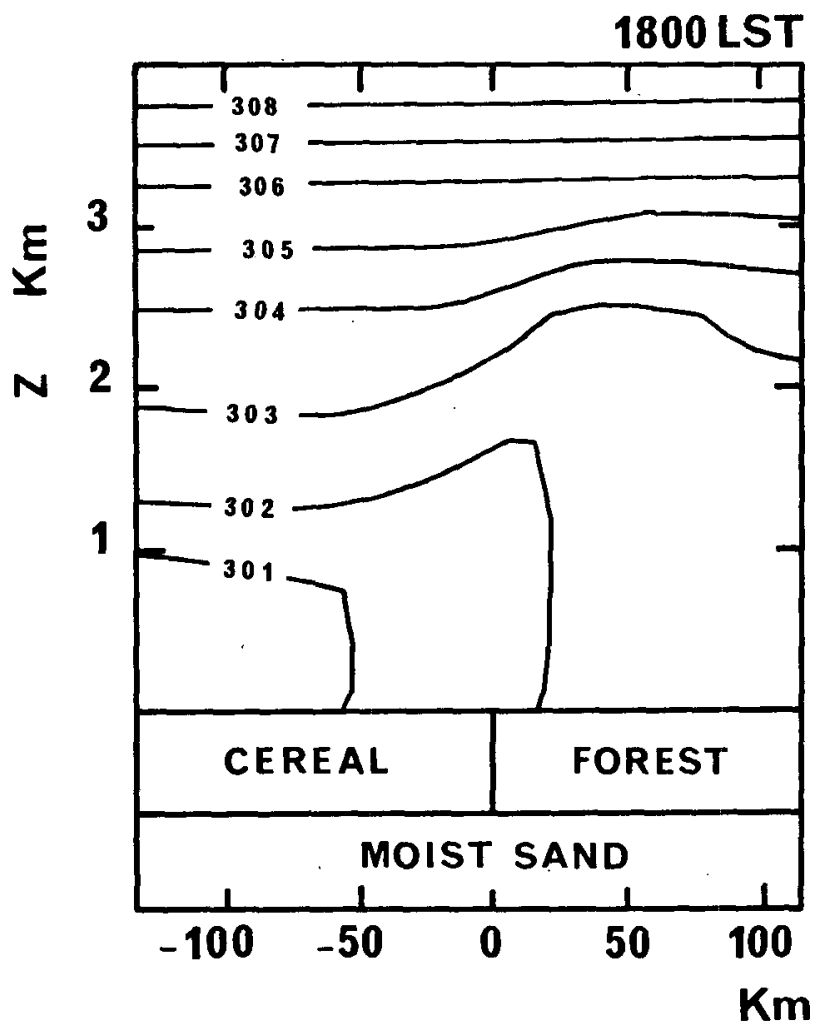

FIG. 16. Vertical cross section of potential temperature (K) at 1800 LST for Experiment 1. 


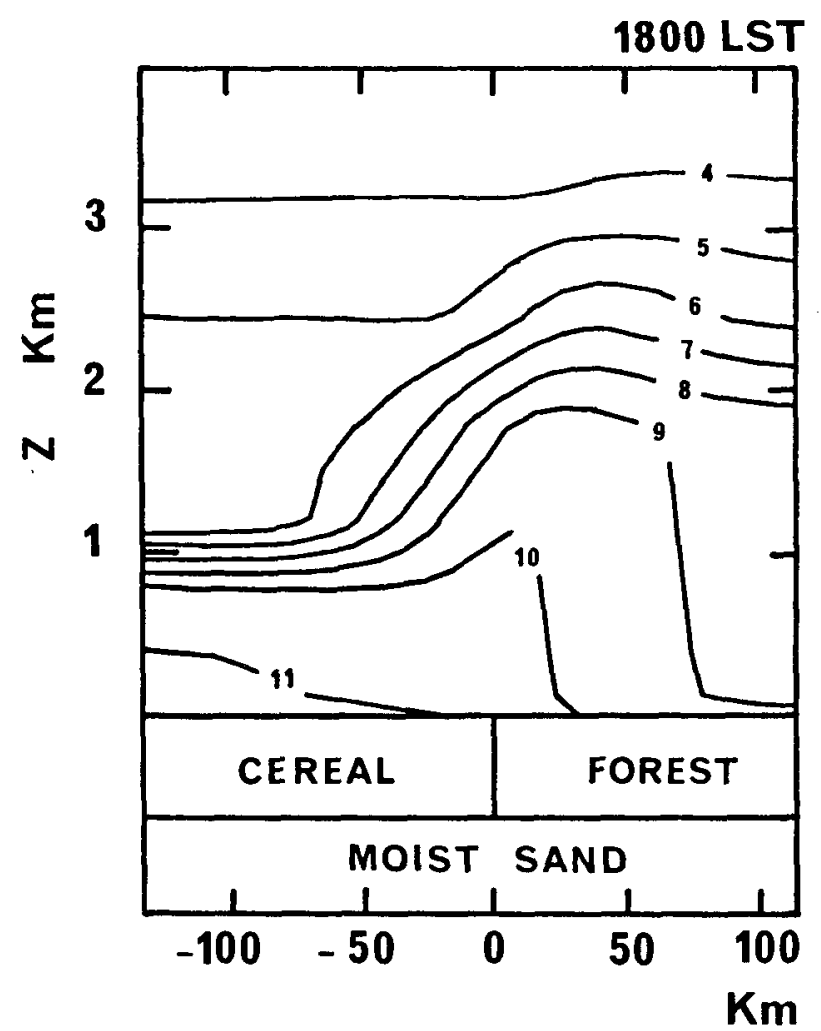

FIG. 17. Vertical cross section of water vapor mixing ratio $\left(\mathrm{g} \mathrm{kg}^{-1}\right)$ at 1800 LST for Experiment 1.

mation. Their results show circulations similar to Ookouchi's during the first hours of simulation. When enough water is present in the atmosphere, however, cloud and rain develop later in the first day of integration, and the circulation is subsequently reinforced through latent heating effects. As the maximum wind velocity produced by the forest breeze is within the range of the values found for the other dry inland simulations of Table 3, the influence of the cereal/forest transition on cloud and rain formation therefore appears likely when there is a favorable synoptic environment.

\section{d. Experiment 2: cereal/forest transition with dry soil in cereal area}

This experiment is performed to study the sensitivity of the results found in the previous section to changes in crop maturity and soil moisture. The parameters for the cereal area (zone A) are taken from Site C2 of Table 1-ripening oats over dry soil. The characteristics are unchanged for the forested zone-conifer forest over moist soil-and for the initial atmospheric profiles as well.

The variations of sensible and latent heat fluxes across the model domain are displayed in Fig. 18. Due to the increased difference in albedo between zones $A$ and $B$, the available energy difference between the cereals and the forest is larger than in Experiment 1. Over
TABLe 3. Maximum wind speed in the PBL associated with various sea- and inland-breeze circulations.

\begin{tabular}{lllr}
\hline & & & \\
& Reference & Clouds & $\begin{array}{r}U_{\max } \\
\left(\mathrm{m} \mathrm{s}^{-1}\right)\end{array}$ \\
\hline Sea/bare-land & Ookouchi et al. (1984) & No & 5.5 \\
& Mahfouf et al. (1987a) & No & 8.0 \\
& Yan and Anthes (1988) & Yes & 11.4 \\
Moist/dry land & Ookouchi et al. (1984) & No & 4.5 \\
& Yan and Anthes (1988) & Yes & 12.4 \\
Grassland/bare-land & Mahfouf et al. (1987a) & No & 2.9 \\
Cereal/conifer & & & \\
forest & This work & No & 4.0 \\
\hline
\end{tabular}

the forest, the Bowen ratio is always close to 1 , since the soil and vegetation properties are unchanged. On the contrary, the latent heat flux is small over the cereals, where nearly all the available energy is exchanged through sensible heat. The latent heat flux therefore shows a discontinuity across the model domain, whereas the sensible heat flux is nearly homogeneous, with an average value of about $300 \mathrm{~W} \mathrm{~m}^{-2}$. The flux distribution is therefore reversed with respect to Experiment 1 , and no circulation is expected as the differential heating is negligible in Experiment 2.

This conclusion is confirmed by Fig. 19, which shows the cross section of the predicted wind field at 1800 LST. Only a very weak pattern is visible, with a maximum horizontal wind around $0.5 \mathrm{~m} \mathrm{~s}^{-1}$ in the low levels. The intensity of the circulations found in Experiments 1 and 2 are further compared in Fig. 20, showing the vertical profiles of the horizontal wind in the lowest $4 \mathrm{~km}$ at $1200 \mathrm{LST}$ and $2100 \mathrm{LST}$. The depth of the mixed layer is also nearly uniform, as seen in Fig. 21, where the potential temperature cross section only shows minor variations near the ground, possibly as the result of larger turbulence intensities at low level

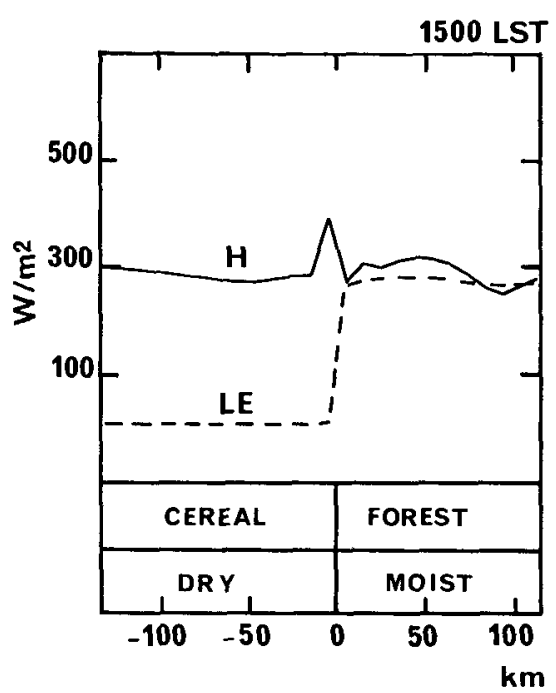

FIG. 18. Horizontal profiles of surface sensible (solid line) and latent (dashed line) heat fluxes $\left(\mathrm{W} \mathrm{m}^{-2}\right)$ at 1500 LST for Experiment 2 . 


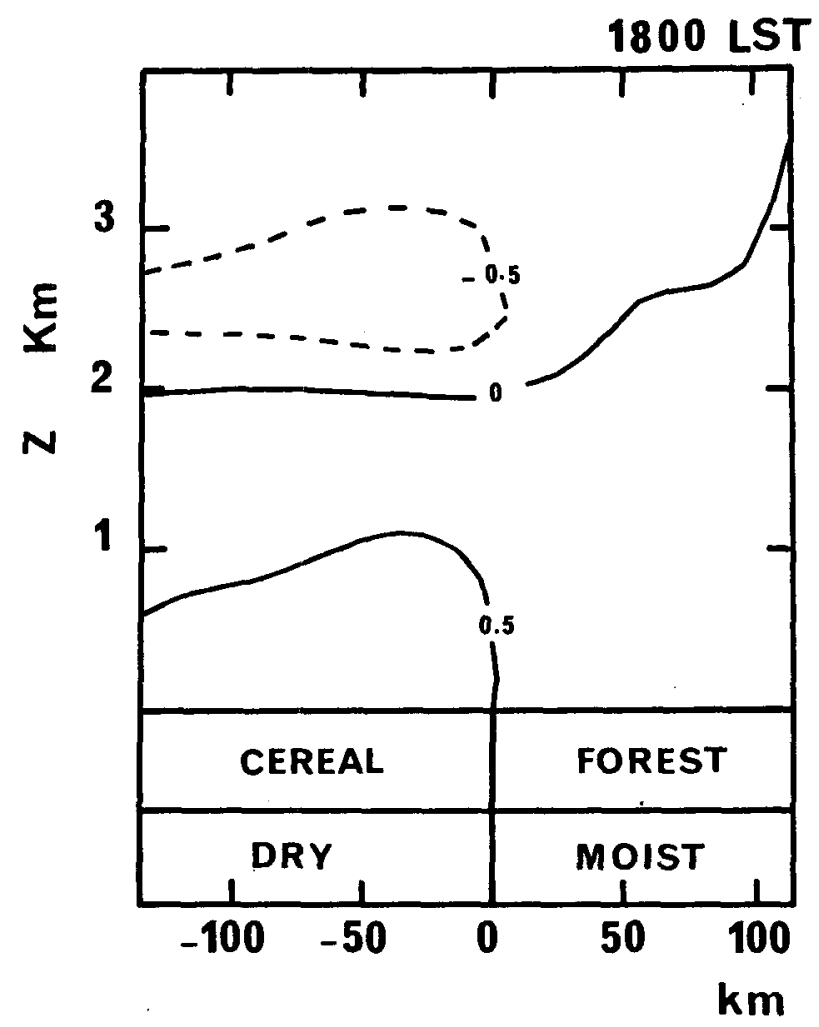

FIG. 19. Vertical cross section of horizontal wind speed $\left(\mathrm{m} \mathrm{s}^{-1}\right)$ at 1800 LST for Experiment 2.

above the rougher forest. The water vapor mixing ratio, displayed in Fig. 22, does of course respond to the horizontal variations in moisture flux and shows a drier boundary layer over the cereals than over the forest, where a significant amount of water is injected.

Finally, Experiment 2 emphasizes the importance of soil moisture and vegetation maturity in surface flux

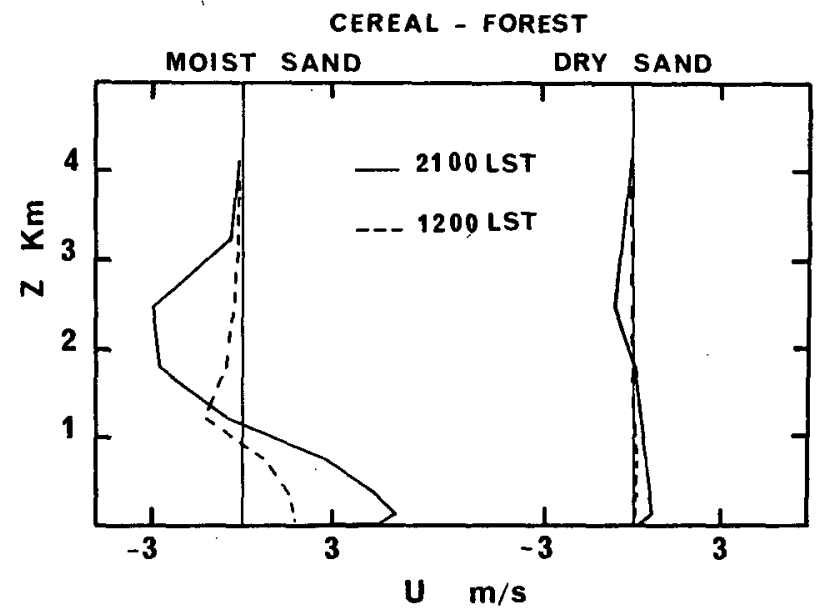

FiG. 20. Comparison of vertical profiles of horizontal wind ( $m$ $s^{-1}$ ) at the boundary between the two vegetation zones, for Experiment 1 (left panel) and Experiment 2 (right panel). Profiles at 1200 LST shown in dashed line, profiles at 2100 LST in solid line.

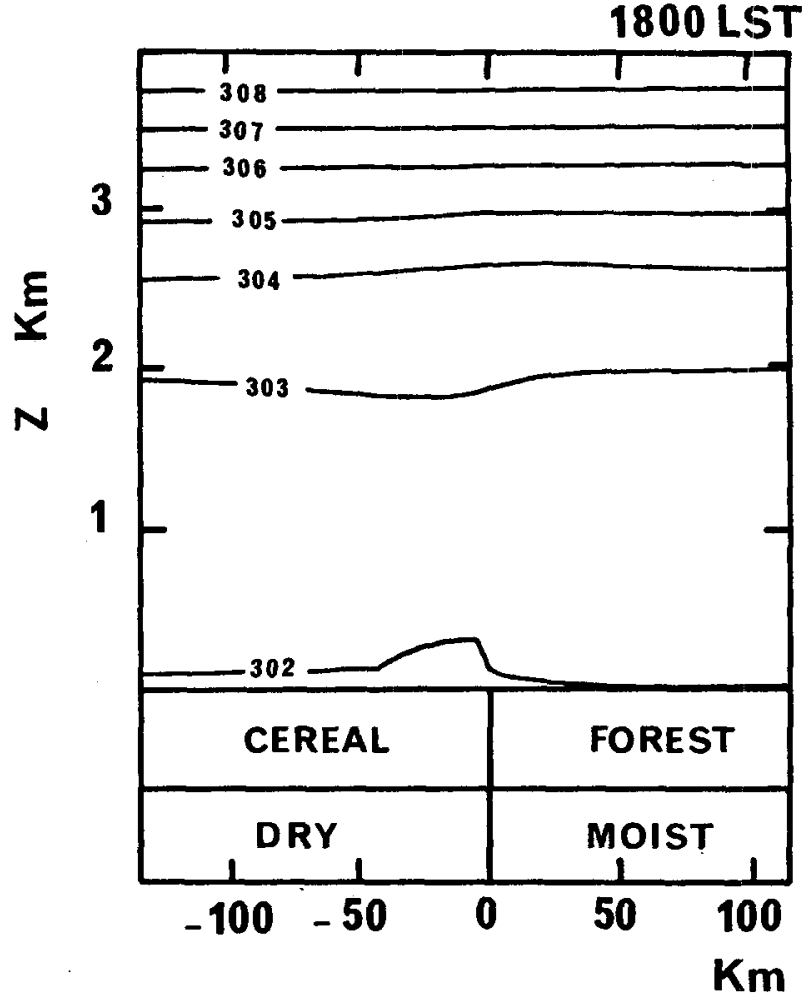

FIG. 21. Vertical cross section of potential temperature ( $K$ ) at 1800 LST for Experiment 2.

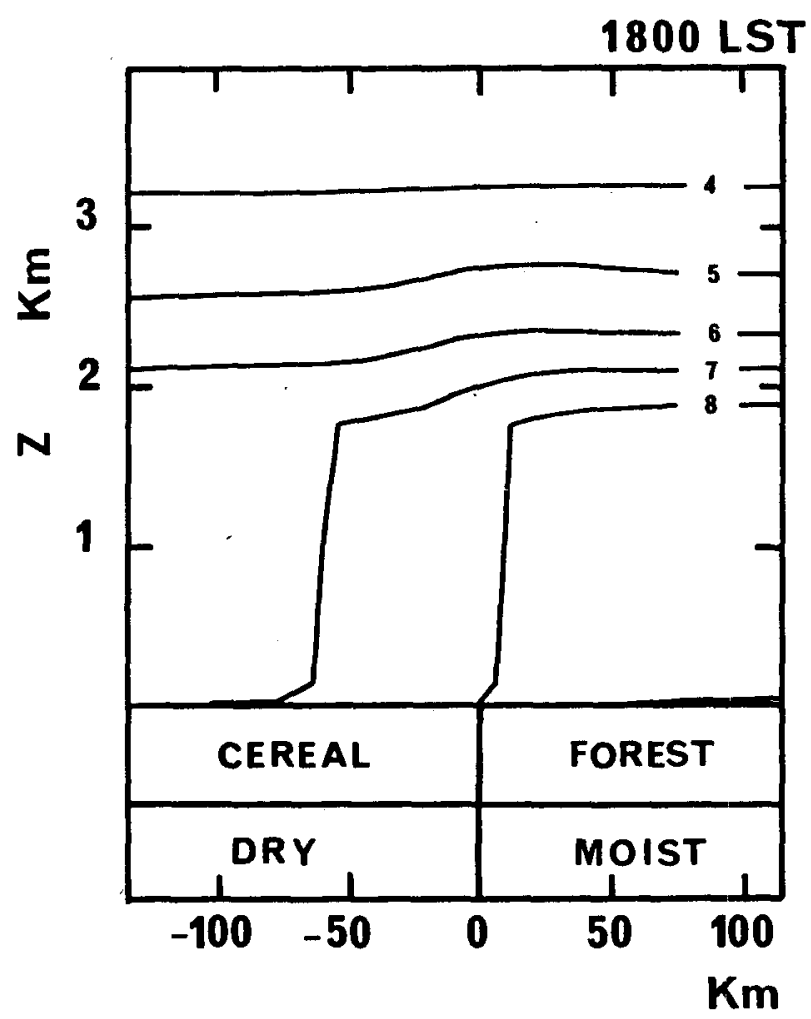

FIG. 22. Vertical cross section of water vapor mixing ratio $\left(\mathrm{g} \mathrm{kg}^{-1}\right)$ at 1800 LST for Experiment 2. 
modeling. The comparison between Experiments 1 and 2 shows that the knowledge of the vegetation distribution has to be complemented with an accurate description of the soil moisture. Because the distribution of the Bowen ratios differs widely depending on the presence or absence of water deficit, the realism of the model predictions is therefore conditioned directly by the accuracy of the available moisture data, except over very moist soil.

\section{Summary and conclusion}

In this paper, the impact of vegetation characteristics on the development of mesoscale circulations has been investigated using an evapotranspiration scheme calibrated against data from the HAPEX-MOBILHY experiment.

First, an improved version of the soil-vegetation scheme of Mahfouf et al. (1987a) has been proposed. The revised scheme includes the computation of leaf water potential, which provides a better description of the feedback limiting the transpiration when the soil becomes very dry or when the atmospheric demand is too high (e.g., dry advection, strong wind). The calibration of this parameterization has been made for three different vegetation types using micrometeorological data from the HAPEX-MOBILHY experiment. It was shown that empirical rules can be proposed to prescribe some of the parameters of the parameterization thereby reducing the number of tunable parameters. Much work, however, remains to be done on this aspect of the problem.

Then, using a two-dimensional numerical model including the revised parameterization, we found that a significant mesoscale circulation develops in response to the thermal contrast between a forest and an adjacent cereal crop, at horizontal scales of $100-200 \mathrm{~km}$. The favorable conditions for this forest-breeze phenomenon are obtained when the soil moisture is readily available, so that the agricultural crop evaporates at high rate due to its low minimal surface resistance. The forest canopy then exchanges more sensible heat with the atmosphere than its surroundings, and the resulting differential heating produces the atmospheric circulation. The intensity of the predicted flow suggests that the boundary between an agricultural crop and a forest might be a prefered location for cloud and rain initiation if there is a favorable synoptic environment.

Finally, it was found that the predicted mesoscale circulation is highly sensitive to the maturity of the agricultural crop and, even more, to the soil moisture availability. The present results therefore show that the accuracy of the available soil moisture data directly determines the accuracy of the surface level predictions made by a mesoscale model, even with dense vegetation cover, except when the soil is very moist.

Acknowledgments. The authors have greatly benefited from helpful comments and suggestions from J.-F. Mahfouf, J. Noilhan, P. Bougeault and J.-Y. Ca- neil. Special thanks go to J.-C. André, J.-P. Goutorbe and A. Perrier who initiated and organized the HAPEX-MOBILHY field program. Of the many individuals who provided us with HAPEX-MOBILHY surface data, we particularly thank $C$. Tarrieu, $M$. Payen, B. Bret, B. Jacquemin, D. Phulpin, C. Valencogne, J. Gelpe, J.-P. Lagouarde and O. Taconet. Our gratitude also goes to W. J. Shuttleworth and J. H. Gash (Institute of Hydrology, U.K.) for providing the micrometeorological measurements over the Landes forest. Skillful technical assistance was also given by J. Duron, who developed the graphic software, R. Pejoux, who solved many computer problems, and J. Squarise, who read the manuscript. This work was supported by grants from Electricité de France and Institut National des Sciences de l'Univers (Prog. Atm. Météo.). Computer resources were made available by E.C.M.W.F. (Reading, U.K.), C.C.V.R. (Palaiseau, France) and Météorologie Nationale (Paris, France). Access to the computer network was provided by C.N.U.S.C. (Montpellier, France).

\section{APPENDIX}

\section{List of Symbols}

$b$ exponent of the soil moisture potential equation (3)

$D_{\eta} \quad$ soil hydraulic diffusivity

$E_{t r}$ transpiration rate

$H$ sensible heat flux

$h_{f} \quad$ average vegetation height

$K_{\eta} \quad$ soil hydraulic conductivity

$K_{\eta s}$ soil saturation hydraulic conductivity

LAI integrated leaf area index

LE latent heat flux

$M_{s t} \quad$ moisture control factor for $r_{s t}$

$u_{*} \quad$ friction velocity

$r_{a} \quad$ atmospheric resistance

$r_{s t} \quad$ stomatal resistance

$r_{s t_{\max }}$ maximum stomatal resistance

$r_{s t_{\max }}$ minimum stomatal resistance

$R e_{c}$ critical Reynolds number for $r_{a}$

$R_{f} \quad$ plant internal resistance

$R_{n} \quad$ net radiation

$R_{r} \quad$ soil root surface resistance

$R_{s w} \downarrow$ downward solar radiation

$S_{s t}$ radiation control factor in $r_{s t}$

$T_{s} \quad$ soil temperature

$\eta \quad$ soil volumetric moisture content

$\eta_{s} \quad$ soil porosity

$\lambda$ soil thermal conductivity

$\rho_{w} \quad$ liquid water density

$\sigma_{f} \quad$ canopy shielding factor

$\psi \quad$ soil moisture potential

$\psi_{f} \quad$ leaf water potential

$\psi_{f c} \quad$ critical leaf water potential

$\psi_{s} \quad$ soil saturation moisture potential

$\psi_{s r} \quad$ rooting zone average soil moisture potential 


\section{REFERENCES}

André, J.-C., J.-P. Goutorbe and A. Perrier, 1986: HAPEX-MOBILHY: A hydrologic atmospheric experiment for the study of water budget and evaporation flux at the climatic scale. Bull. Amer. Meteor. Soc, 67, 138-144.

,,,--- F. Becker, P. Bessemoulin, P. Bougeault, Y. Brunet, W. Brutsaert, T. Carlson, R. Cuenca, J. Gash, J. Gelpe, P. Hildebrand, P. Lagouarde, C. Lloyd, L. Mahrt, P. Mascart, C. Mazaudier, J. Noilhan, C. Ottlé, M. Payen, T. Phulpin, R. Stull, J. Shuttleworth, T. Schmugge, O. Taconet, C. Tarrieu, R. M. Thépenier, C. Valencogne, D. Vidal-Madjar and A. Weill, 1988a: HAPEX-MOBILHY: First results from the special observing period. Ann. Geofis., 6(5), 477-492.

-, P. Bougeault, J.-F. Mahfouf, P. Mascart, J. Noilhan and J.-P. Pinty, 1989: Impact of forest on mesoscale meteorology. Phil. Trans. R. Soc. Lond. B., to appear.

Anthes, R. A., 1984: Enhancement of convective precipitation by mesoscale variations in vegetative covering in semiarid regions. J. Climate Appl. Meteor., 23, 541-554.

Blondin, C. A., 1987: A revised surface and sub-surface scheme in the ECMWF model., E.G.S. XII Assembly, Terra Cognita, 7, S II-1.3.

Choudhury, B. J., and S. B. Idso, 1985a: An empirical model for stomatal resistance of field-grown wheat. Agric. For. Meteor., $36,65-82$.

- , and —-, 1985b: Evaluating plant and canopy resistances of field-grown wheat from concurrent diurnal observations of leaf water potential, stomatal resistance, canopy temperature, and evapotranspiration flux. Agric. For. Meteor., 34, 67-76.

Clapp, R. B., and G. M. Hornberger, 1978: Empirical equations for some soil hydraulic properties. Water Resour. Res., 14, 601604.

Deardorff, J. W., 1978: Efficient prediction of ground surface temperature and moisture, with inclusion of a layer of vegetation. J. Geophys. Res., 83, 1889-1903.

Denmead, O. T., 1976: Temperate cereals. Vegetation and the Atmosphere, Vol. 2, J. L. Monteith, Ed., Academic Press, 1-31.

de Vries, D. A., 1975: Heat transfer in soils. Heat and Mass Transfer in the Biosphere, Vol. 1, D. A. de Vries and N. H. Afgan, Eds., Scripts Book Co., 594 pp.

Dickinson, R. E., 1984: Modeling evapotranspiration for three-dimensional global climate models. Climate Processes and Climate Sensitivity, J. E. Hanson and T. Takahashi, Eds., Amer. Geophys. Union, Geophys. Monogr., 29, 58-72.

Federer, C. A., 1982: Transpirational supply and demand: plant, soil, and atmospheric effects evaluated by simulation. Water Resour. Res., 18, 355-362.

Garrett, A. J., 1982: A parameter study of interactions between convective clouds, the convective boundary layer, and a forested surface. Mon. Wea. Rev., 110, 1041-1059.

Gash, J. H. C., W. J. Shuttleworth, C. R. Lloyd, J.-C. André, J.-P. Goutorbe and J. Gelpe, 1989: Micrometeorological measurements in Les Landes forest during HAPEX-MOBILHY. Agric. For. Meteor., 46, 131-147.

Jarvis, P. J., 1976: The interpretation of the variations in leaf water potential and stomatal conductance found in canopies in the field. Phil. Trans. R. Soc. Lond. B., 273, 593-610.

Katerji, N. B., 1982: Etude et modélisation des transferts hydriques dans le système sol-plante-atmosphère. Dr. Sc. dissertation, Université de Paris VII, 296 pp.
Kimball, B. A., R. D. Jackson, F. S. Nakayama, S. B. Idso and R. J. Reginato, 1976: Soil-heat flux determination: temperature gradient method with computed thermal conductivities. Soil Sci. Amer. J., 40, 25-28.

Mahfouf, J.-F., E. Richard and P. Mascart, 1987a: The influence of soil and vegetation on the development of mesoscale circulations. J. Climate Appl. Meteor., 26, 1483-1495.

- E. Eichard, P. Mascart, E. C. Nickerson and R. Rosset, 1987b: A comparative study of various parameterizations of the planetary boundary layer in a mesoscale model. J. Climate Appl. Meteor., 26, 1672-1695.

McCumber, M. C., 1980: A numerical simulation of the influence of heat and moisture fluxes upon mesoscale circulations. Ph.D. dissertation, University of Virginia, $255 \mathrm{pp}$.

- , and R. A. Pielke, 1981: Simulation of the effects of surface fluxes of heat and moisture in a mesoscale numerical model. Part I: Soil model. J. Geophys. Res., 86, 9929-9938.

Nickerson, E. C., E. Richard, R. Rosset and D. R. Smith, 1986: The numerical simulation of clouds, rain, and airflow over the Vosges and Black Forest mountains: a meso- $\beta$ model with parameterized microphysics. Mon. Wea. Rev., 114, 398-414.

Ookouchi, Y., M. Segal, R. C. Kessler and R. A. Pielke, 1984: Evaluation of soil moisture effects on the generation and modification of mesoscale circulations. Mon. Wea. Rev., 112, 2281-2292.

Physick, W. L., 1980: Numerical experiments on the inland penetration of the sea breeze. Quart. J. Roy. Meteor. Soc., 106, 735746.

Sellers, P. J., and J. L. Dorman, 1987: Testing the simple biosphere model ( $\mathrm{SiB})$ using point micrometeorological and biophysical data. J. Climate Appl. Meteor., 26, 622-651.

- , Y. Mintz, Y. C. Sud and A. Dalcher, 1986: A simple biosphere model $(\mathrm{SiB})$ for use within general circulation models. J. Atmos. Sci., 43, 505-531.

Simpson, J. E., D. A. Mansfield and J. R. Milford, 1977: Inland penetration of sea-breeze fronts. Quart. J. Roy. Meteor. Soc., 103, 47-76.

Taconet, O., R. Bernard and D. Vidal-Madjar, 1986: Evapotranspiration over an agricultural region using a surface flux/temperature model based on NOAA-AVHRR data. J. Climate Appl. Meteor., 25, 284-307.

Thom, A. S., J. B. Stewart, H. R. Oliver and J. H. C. Gash, 1975; Comparison of aerodynamic and energy budget estimates of fluxes over a pine forest. Quart. J. Roy. Meteor. Soc., 101, 93105.

Wetzel, P. J., and J.-T. Chang, 1984: Concerning the relationship between evapotranspiration and soil moisture. J. Climate Appl. Meteor., 26, 18-27.

$\longrightarrow$, and - 1988: Evapotranspiration from nonuniform surfaces: a first approach for short-term numerical weather prediction. Mon. Wea. Rev., 116, 600-621.

Wilson, M. F., A. Henderson-Sellers, R. E. Dickinson and P. J. Kennedy, 1987: Sensitivity of the Biosphere-Atmosphere Transfert Scheme (BATS) to the inclusion of variable soil characteristics. J. Climate Appl. Meteor., 26, 341-362.

Yan, H., and R. A. Anthes, 1987: The effect of latitude on the sea breeze. Mon. Wea. Rev., 115, 936-956.

- , and - 1988: The effect of variations in surface moisture on mesoscale circulations. Mon. Wea. Rev., 116, 192-208.

Zhang, D., and R. A. Anthes, 1982: A high-resolution model of the planetary boundary layer--sensitivity tests and comparisons with SESAME-79 data. J. Appl. Meteor., 21, 1594-1609. 